\title{
Molecular and cellular development of spinal cord locomotor circuitry
}

\author{
Daniel C. Lu, Tianyi Niu and William A. Alaynick* \\ Department of Neurosurgery, David Geffen School of Medicine, University of California, Los Angeles, Los Angeles, CA, USA
}

The spinal cord of vertebrate animals is comprised of intrinsic circuits that are capable of sensing the environment and generating complex motor behaviors. There are two major perspectives for understanding the biology of this complicated structure. The first approaches the spinal cord from the point of view of function and is based on classic and ongoing research in electrophysiology, adult behavior, and spinal cord injury. The second view considers the spinal cord from a developmental perspective and is founded mostly on gene expression and gain-of-function and loss-of-function genetic experiments. Together these studies have uncovered functional classes of neurons and their lineage relationships. In this review, we summarize our knowledge of developmental classes, with an eye toward understanding the functional roles of each group.

Keywords: interneuron, motor neuron, transcription factor, locomotion, sensory, circuit

OPEN ACCESS

Edited by:

Robert W. Burgess,

The Jackson Laboratory, USA

Reviewed by:

Bruce R. Johnson, Cornell University, USA

Francisco Javier Alvarez,

Emory University, USA

*Correspondence:

William A. Alaynick,

Department of Neurosurgery, David

Geffen School of Medicine, University

of California, Los Angeles,

650 Charles East Young Drive,

Wasserman Building, Room 562,

Los Angeles, CA 90095, USA

walaynick@mednet.ucla.edu

Received: 02 April 2015 Accepted: 30 May 2015

Published: 16 June 2015

Citation:

Lu DC, Niu T and Alaynick WA (2015) Molecular and cellular development of spinal cord locomotor circuitry.

Front. Mol. Neurosci. 8:25

doi: 10.3389/fnmol.2015.00025

\section{Introduction}

More than 20 distinct embryonic classes of neurons have been described in the spinal cord, and the developmental sources of their diversity have been elucidated over the past decade (Figure 1). This cellular diversity has been organized into a schema that defines major groups of neurons based on their expression of embryonic transcription factors. The major characteristics of these classes their generation, transcription factors, subsets, positions, neurotransmitters, connections, and functions are summarized here.

Spinal cord development is subject to phylogenetically ancient organizing principles such as those that guide segmentation from the invertebrates, such as arthropods, to the vertebrates, such as mammals. Cellular identities in vertebrate spinal cord are specified during development along the three basic spatial axes of the embryonic body plan - rostral-caudal, dorsal-ventral, and medial-lateral. In addition, there is a temporal influence of development on these spatial coordinates such that distinct cell fates emerge at different times during development. This yields a four dimensional system for establishing spinal neuron cell fate that has been reviewed extensively (Jessell, 2000; Jankowska, 2001; Lee and Pfaff, 2001; Muroyama et al., 2002; Helms and Johnson, 2003; Goulding and Pfaff, 2005; Kiehn, 2006; Ladle et al., 2007; Stepien and Arber, 2008; Dasen and Jessell, 2009; Goulding, 2009; Grillner and Jessell, 2009; Hegarty et al., 2013).

To summarize briefly, the rostral-caudal positional identities are coordinated by opposing gradients of fibroblast growth factor (Fgf, caudalizing) and retinoic acid (RA, rostralizing; Figure 2; Muhr et al., 1999; Liu et al., 2001; Dasen et al., 2008). The dorsal-ventral axis is governed by ventralizing Sonic hedgehog (Shh) produced by the floorplate, and dorsalizing signals from the roof plate such as bone morphogenetic proteins (BMPs) and Wnts (which are members of the Wingless + MMTV integrants, Int family). These diffusible morphogens form gradients that activate specific transcriptional responses at defined points in the gradient (Roelink et al., 1994; Liem et al., 1995; 


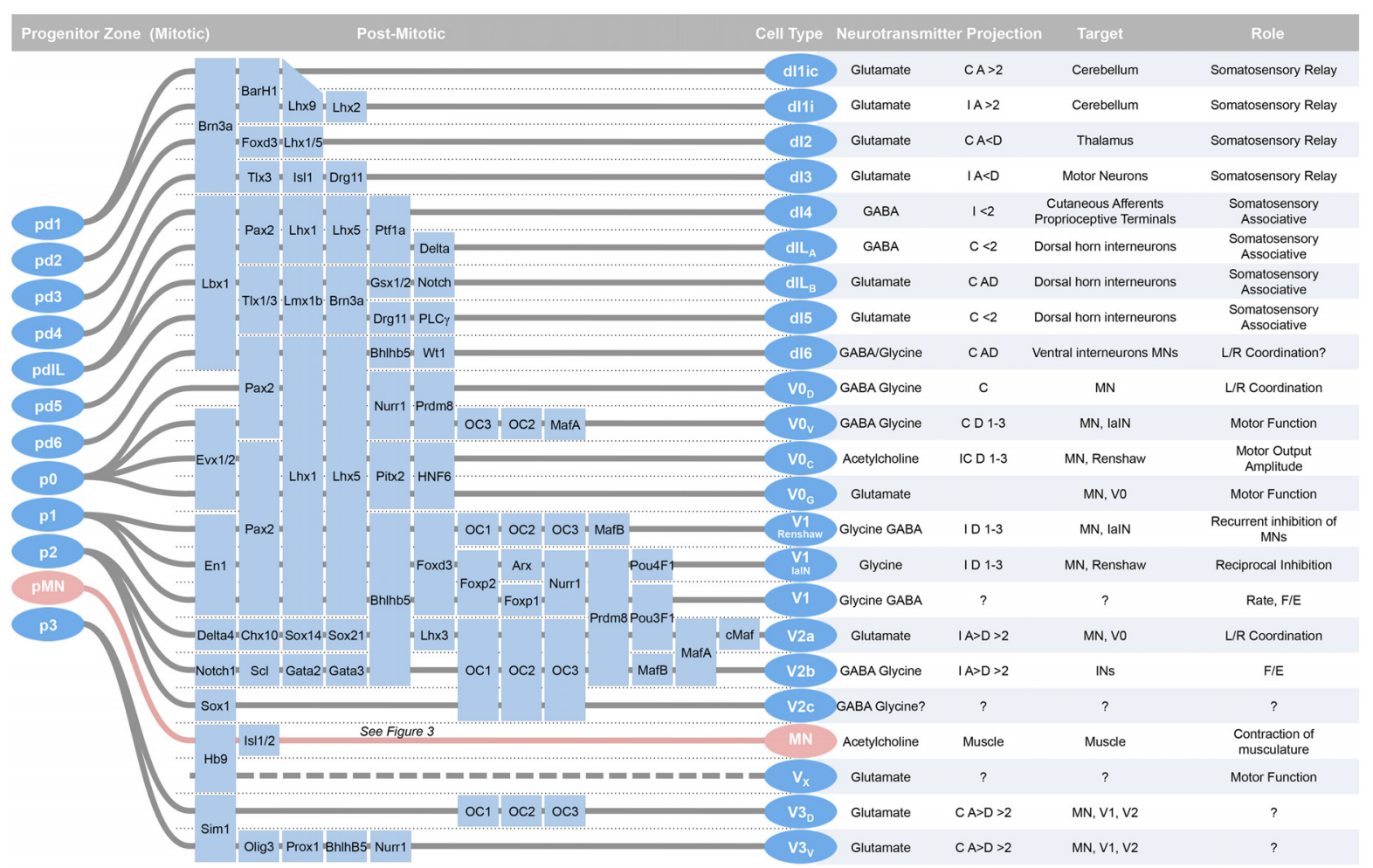

Projection Code
I: Ipsilateral
C: Contralateral
A: Ascending
D: Descending
1: Number of Segments

FIGURE 1 | At around mid-gestation, progenitors exit the cell cycle and begin to take up characteristic setting positions, extend axons, and express transcription factors and neurotransmitter biosynthetic enzymes. Over the last week of development, 23 classes of neurons can be defined by transcription factor expression. Adapted from Alaynick et al. (2011).

Ericson et al., 1996; Lee et al., 1998; Megason and McMahon, 2002; Muroyama et al., 2002; Timmer et al., 2002). These transcriptional programs first specify and reinforce the identities of progenitor cells, and second, act to oppose adjacent transcriptional programs and sharpen boundaries between progenitor zones. In the ventral cord, these transcription factors are grouped into two classes, those that are inhibited by Shh (Class I) and those that are activated by Shh (Class II; Briscoe et al., 2000). Spinal cord development is also organized along a medial-lateral axis dividing progenitor cells that are located adjacent to the lumen of the neural tube, medially, whereas differentiating progeny migrate laterally. Over time, a given progenitor domain defined by these spatial coordinates may sequentially produce distinct cellular classes.

Within an idealized spinal cord segment, this system establishes thirteen progenitor pools along the dorsal-ventral axis (Figure 2). There are eight dorsal interneuron progenitor divisions, pd1-6 and the late-born pdILA and pdILB, four ventral interneuron progenitor divisions, $\mathrm{p} 0-3$, and one motor neuron progenitor domain, pMN (Alaynick et al., 2011). The identities of these domains are predominantly defined by basic-helix-loop-helix (bHLH) domain transcription factors, such as Ngn, Olig2, and Math (Bermingham et al., 2001; Gowan et al., 2001; Novitch et al., 2001; Scardigli et al., 2001; and homeodomain proteins, such as Pax3, Dbx1, and Nkx6.1 (Briscoe et al., 2000; Vallstedt et al., 2001; Subsequently, additional transcription factors, predominantly of the LIMhomeodomain family, such as Lhxl and Isl1, are expressed in sub-groups of these domains, further refining cell fate into at least 23 distinct classes (Tsuchida et al., 1994; Gross et al., 2002; Muller et al., 2002; Thaler et al., 2002; Cheng et al., 2004).

\section{Ventral Compartment of Distinct Progenitor Cells}

\section{pMN Fate}

The pMN cell domain gives rise to: (1) 100s of genetically distinct groups of cholinergic alpha motor neurons clustered into motor pools that innervate specific skeletal muscles; (2) gamma motor neurons that innervate intrafusal fibers of specific skeletal 


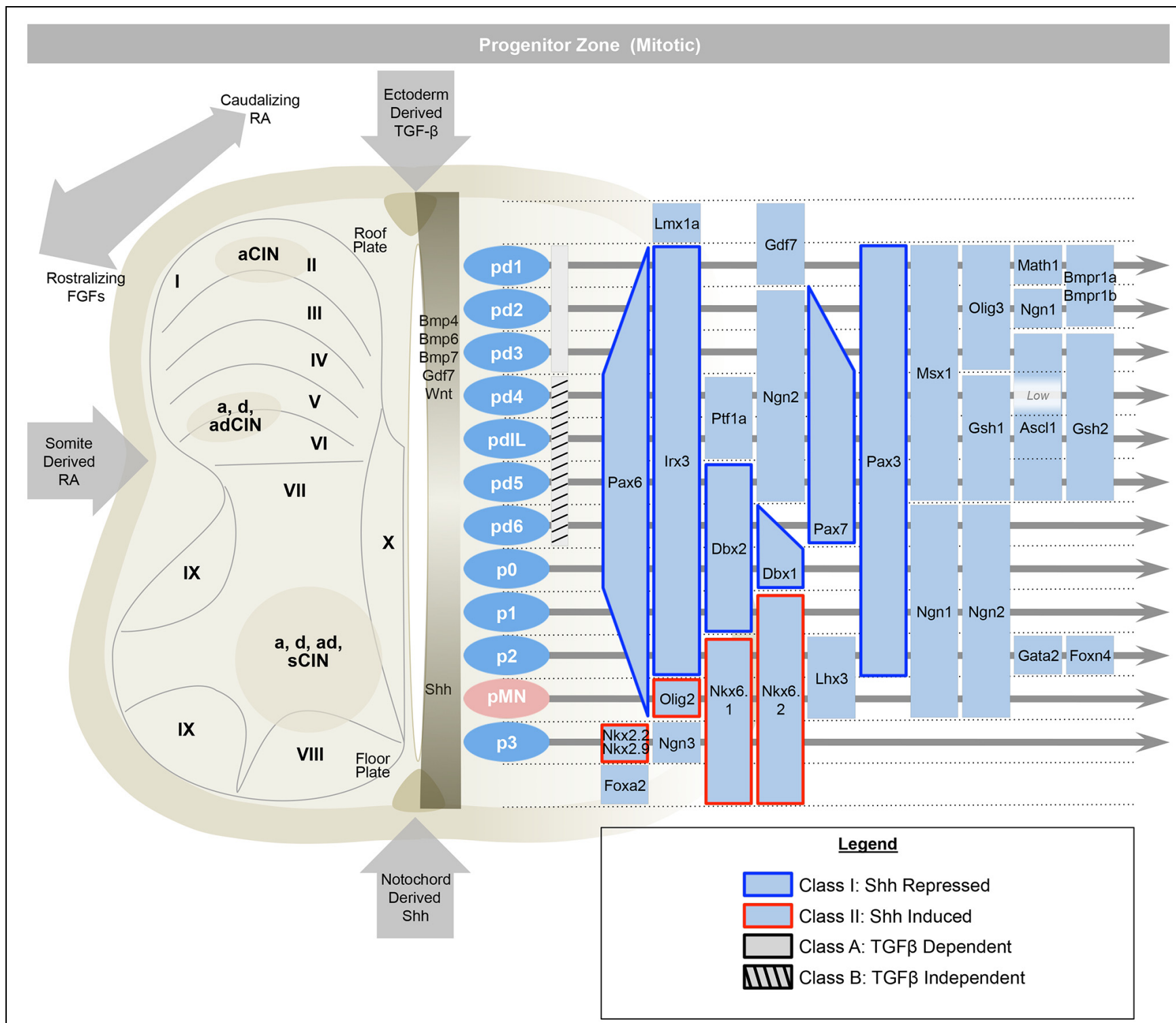

FIGURE 2 | The early spinal cord (e9.5-e11) is influenced by Sonic-hedgehog (Shh) ventrally, ectoderm-derived TGF-beta family members dorsally, and retinoic acid from the somite, laterally. This establishes 13 progenitor domains (including the late born pdILA and pdILB) that express transcription factors that help to define progenitor identities and refine boundaries between progenitor domains. Ventrally, Class I transcription factors are repressed by Shh (e.g., Irx3), while Class II are induced (e.g., Olig2). Similarly, the dorsal-most domains, pd1-pd3, are dependent on TGF-beta and the pd4-pd6 and pdlL domains are independent of TGF-beta signaling. Adapted from Alaynick et al. (2011). muscles for proprioception; (3) the predominantly thoracic (T112 , and to L1 and L2 in some species) cholinergic preganglionic sympathetic neurons; (4) the cholinergic parasympathetic motor neurons in the sacral (S2-4) cord; and (5) oligodendrocytes found throughout the spinal cord (Figure 3). The motor neurons that effect muscle movement are primarily alpha, with fewer beta, motor neurons.

\section{pMN Birth and Early Development}

The recognition that a supernumerary notochord could induce the generation of additional motor neurons led to the identification of the diffusible morphogen, Shh, that induces neural precursors to a MN fate (Watterson, 1965; Roelink et al., 1994). An early marker of motor neuron development, the LIM-HD transcription factor, Isl1, indicated that motor neuron precursors are born between $\mathrm{HH}$ Stages 15 and 17 in chick and beginning at E9.5 ( $\sim 25$ somites) in mouse (Figure 4A; Ericson et al., 1992; Roelink et al., 1994; Pfaff et al., 1996; Gould et al., 2006). These progenitors will give rise to somatic alpha motor neurons that innervate skeletal muscle in the medial and lateral motor columns (LMCs), gamma motor neurons that innervate intrafusal fibers of the muscle spindles, and preganglionic motor neurons of the autonomic nervous system. Generation of each of these classes and their organization 


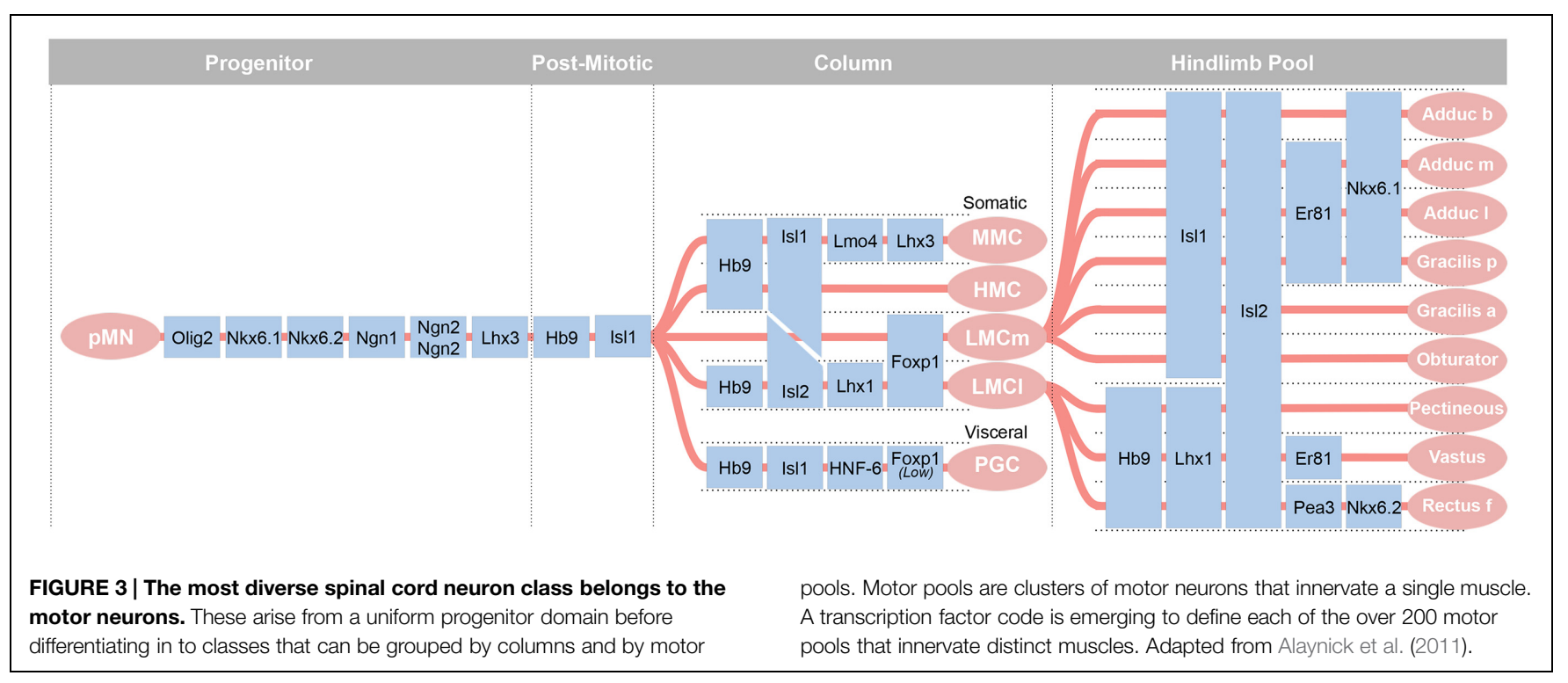

into motor columns and motor pools requires the subsequent expression of additional transcription factors (Lin et al., 1998; Dasen et al., 2005, 2008). These factors then drive the unique characteristics of that motor pool, such as guidance to the target and establishment of proper connectivity with sensory neurons and interneurons. Interestingly, this transcriptionally defined program is complemented by activity-dependent processes that control cellular connectivity and function (Hanson and Landmesser, 2004; Myers et al., 2005). In the case of gamma motor neurons, the nuclear receptor Erry is expressed in these motor neurons and their survival is dependent on GDNF signaling (Gould et al., 2008; Friese et al., 2009; Shneider et al., 2009; Ashrafi et al., 2012).

The motor neuron progenitor domain is ventral to the Irx3 expressing p2 domain that delimits Olig2 expression and is dorsal to the p3 domain that expresses $N k \times 2.2$ and $N k x 2.9$ to delimit Pax6 expression. The expression of $N k x 6.1$ and $N k x 6.2$ acts to limit transcription factor expression to Olig2, that in turn drives the expression of $\mathrm{MN}$ transcription factors $\mathrm{Hb} 9$ (Mnr2 in chick), and Ngn2 (Briscoe et al., 2000; Sander et al., 2000; Vallstedt et al., 2001; Shirasaki and Pfaff, 2002). Hb9, expressed during the final cell division of pMNs, is sufficient to drive the expression of Isll, Isl2, Lhx3, and ChAT - as well as its own expression-establishing pMN independence from Shh (Tanabe et al., 1998). Like Mnr2, the HD transcription factor, $\mathrm{Hb}$, can induce the formation of motor neurons when ectopically expressed. Loss of $\mathrm{Hb} 9$ in mouse, however, results in ectopic upregulation of a V2 IN marker gene, Chx10, but does not result in complete loss of motor neurons or of fictive locomotion (Arber et al., 1999; Thaler et al., 1999; Alaynick, Pfaff unpublished observations).

\section{Motor Neuron Subtypes \\ The Medial and Hypaxial Motor Columns (MMC and HMC)}

The medial sub-group of motor neurons innervates axial musculature and is found the length of the spinal cord. There are two divisions of this group, the medial motor column (MMC) and the hypaxial motor column ( $\mathrm{HMC}$ or $\mathrm{MMCl}$ ). Both express $I s l 1$ and $I s l 2$, although the ratio of expression varies, with greater Isl 1 expression in the HMC than MMC at E11.5 and greater Isl2 in the MMC than HMC by E13.5 in mouse (Tsuchida et al., 1994; Thaler et al., 2004). The MMC innervates dorsal or epaxial musculature, while HMC innervates ventral or hypaxial musculature. Initially all motor neuron progenitors express the LIM homeodomain transcription factor, Lhx3. Lhx3 expression is maintained in the MMC while $L h \times 3$ expression is downregulated in the HMC and LMC (Tsuchida et al., 1994). Motor neuron ( $\mathrm{Hb} 9$ promoter) dependent expression of $L h \times 3$ results in conversion of LMC motor neurons to a MMC identity (Sharma et al., 2000).

\section{The Lateral Motor Column (LMC)}

At limb levels, the 50 or so muscles of the limb are innervated by motor neurons occupying a lateral motor column (Landmesser, 1978). Neurons of the lateral portion of the LMC (LMCl) are later born than the MMC motor neurons, and like the cortex, migrate in an inside-out arrangement such that LMC neurons are born in the proliferative ventricular zone of the pMN domain and then migrate through the MMC to form the LMC. While initially expressing $L h \times 3$, a hallmark of MMC identity, these motor neurons down-regulate $L h x 3$ by an unknown mechanism and begin to express transcription factors not found in MMC that are definitive for LMC identity. The factors include Foxp1, Lim1, and the enzyme Raldh2 (Sharma et al., 1998, 2000; Sockanathan and Jessell, 1998). The lateral motor column has lateral (LMCl) and medial (LMCm) divisions that innervate the dorsal and ventral portions of the limb, respectively, and these cell fates are partially regulated by RA signaling (Sockanathan et al., 2003; Ji et al., 2006). In the $\mathrm{LMCl}$, Lim 1 and $H b 9$ are expressed while Isl1 is downregulated. In the $\mathrm{LMCm}$, there is low $\mathrm{Hb} 9$ and maintained Isll expression. The LMCm and LMCl both express Isl2, which is downregulated in the MMC and HMC (Misra et al., 2009). The $\mathrm{LMCm}$ and $\mathrm{LMCl}$ are further subdivided into motor pools, each 


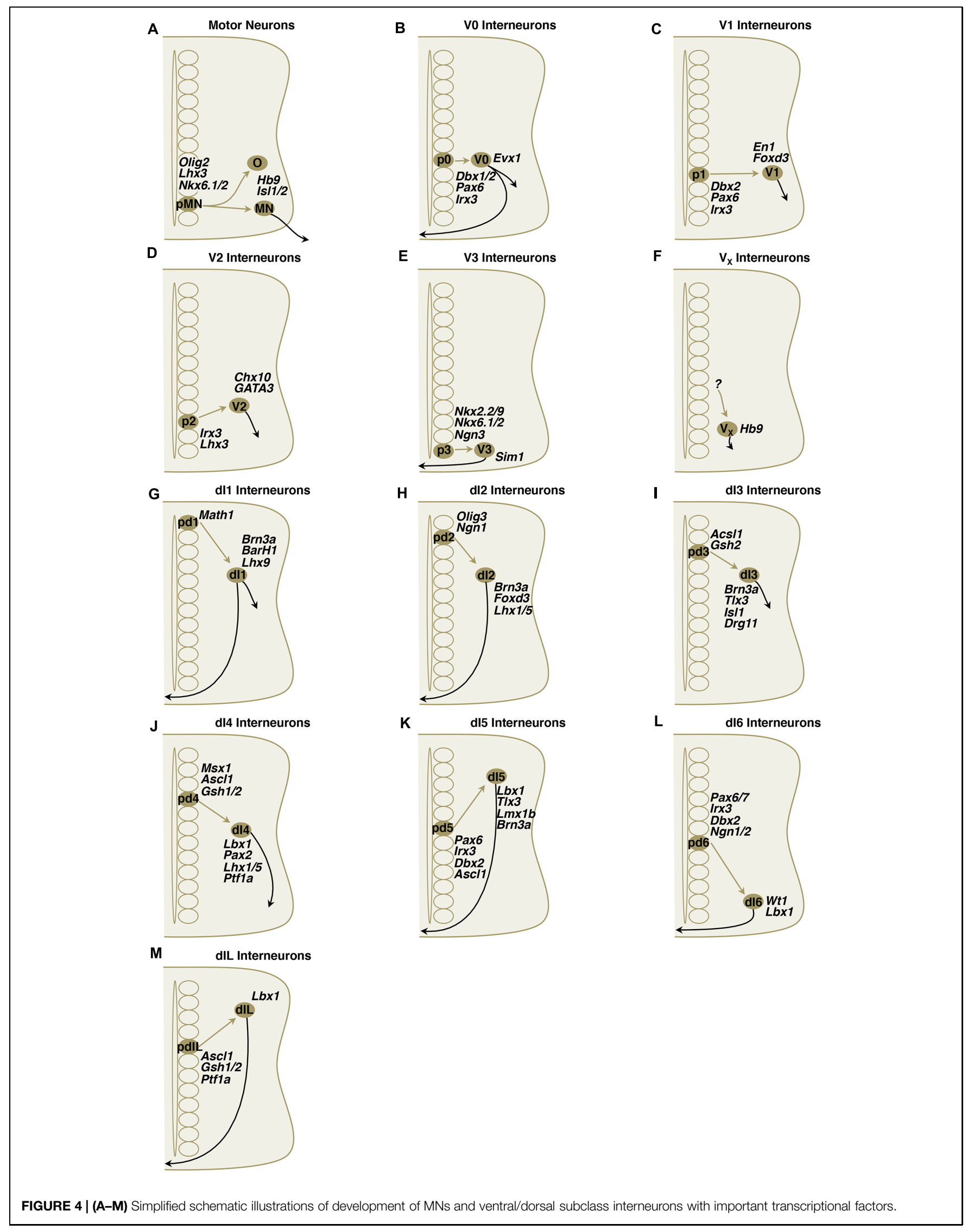


innervating a specific muscle of the limb. These individual motor pools are defined by their expression of Ets and $N k x$ transcription factors that constitute a more refined transcriptional code (De Marco Garcia and Jessell, 2008).

The rostro-caudal regions of the LMC appear to be determined in part by homeobox (Hox) genes. Hox6 is characteristic of brachial level, Hox 9 of thoracic and Hox10 of lumbar. Disruption of the Hox genes in mouse or chick has shown that these boundaries can be profoundly altered to create an expansion of lateral motor columns into thoracic regions (Jung et al., 2010). More strikingly, loss of the Hox co-factor Foxp1 disrupts the ability of motor neurons to incorporate the homeobox code for spatial information, and results in a loss of defined motor pools in the LMC (Dasen et al., 2008).

\section{Preganglionic Motor Neurons (PGC)}

Preganglionic motor neurons of the sympathetic nervous system are the most dorsal motor neurons and can be identified by their expression of ChAT, NADPH Diaphorase, and some members of the one-cut transcription factor class (Francius and Clotman, 2010). Preganglionic motor neurons are also dependent on the downregulation of Lhx3 and are lost with continued, $\mathrm{Hb}$ dependent expression of $L h x 3$ in all motor neurons, or loss of Foxp1 or Isl2 (Sharma et al., 2000; Thaler et al., 2004; Dasen et al., 2005, 2008).

\section{Spinal Interneurons}

A great deal has been learned about the development of discrete classes of interneurons by describing them by electrophysiology, behavioral output, and by expression of proteins involved in transcription, neurotransmitter signaling, and intracellular signaling. Currently, this schema has defined over 20 interneuron types in the spinal cord. While one can argue that every neuron has a unique molecular/genetic expression profile, dendritic arborization and axonal projection pattern, this grouping schema has been useful in organizing interneurons into functionally related groups.

Historically, two broad groups have been defined: the "V" interneurons with progenitors that are found in the ventral cord and are grossly associated with motor function, and a dorsal Interneuron, dI class, associated predominantly with sensory processing. Most studies have examined development within a single or a few segments. A recent study examined rostrocaudal differences at one time point, e12.5 (Francius et al., 2013). This showed that subclasses of ventral interneurons (V0, V1, V2, and V3) exhibit distinct organizational patterns at brachial, thoracic and lumbar levels of the developing spinal cord. Furthermore, each cardinal "V"' class of ventral interneurons can be subdivided into several subsets according to further combinatorial expression of transcription factors (Francius et al., 2013). Given these caveats that likely apply to other interneuron classes, the $\mathrm{V}$ and $\mathrm{dI}$ interneuron classifications are a simplification with exceptions, some of which are listed below. Despite these limitations, the V and dI schema is a useful approach to the subject.

\section{V0 Interneuron Characteristics}

Local projecting V0 neurons are a population of primarily contralateral, with some ipsilateral projecting neurons with inhibitory or excitatory identity that send axons 2-4 spinal segments rostrally (Moran-Rivard et al., 2001; Pierani et al., 2001). They receive inputs from ipsilaterally projecting Chx10 ${ }^{+}$ glutamatergic V2a interneurons (Crone et al., 2008; Figure 5). They are the dorsal-most ventral progenitor pool and are characterized by their expression of the $D b x$ (developing brain homeobox) homeodomain transcription factor, Evx1/2 (evenskipped homeobox 1; Figure 4B). $D b x 1$ and $D b x 2$ are expressed in dividing cells, although $D b x 1$ may be briefly expressed in postmitotic cells (see V1 discussion Pierani et al., 1999). Four V0 interneuron subclasses have been described to date: $\mathrm{V} 0_{\mathrm{V}}, \mathrm{V} 0_{\mathrm{D}}$, $\mathrm{V0}$ C, and $\mathrm{V0}_{\mathrm{G}}$ (Pierani et al., 1999, 2001; Moran-Rivard et al., 2001; Lanuza et al., 2004; Zagoraiou et al., 2009). Early studies addressed the V0 class by eliminating $D b x 1$ and showing that the $E v x 1^{+} \mathrm{V}_{\mathrm{V}}$ subclass was lost because these neurons become fated to an $\mathrm{EnI}^{+} \mathrm{V} 1$-like subclass and astrocytes (Pierani et al., 2001; Lanuza et al., 2004). Because Dbx1 is transiently expressed, a $D b x 1^{\text {LacZ }}$ knock-in allele was used to show that with loss of $D b x 1$, E18.5 embryos retained $40 \%$ of the $\beta \mathrm{gal}^{+}$cells and resulted in a $25 \%$ expansion in the number of $\mathrm{Lbx1}^{+} \mathrm{Pax2}^{+}$dl6-like commissural neurons (Lanuza et al., 2004). By perinatal time points, genetic strategies to track $D b x 1^{+}$cells using $\beta$ gal find that most of these cells are neural by expression of $\mathrm{NeuN}$ and are found in lamina VIII where commissural interneurons reside. Lineage labeling of Dbx1-derived cell reveals a large abundance of glia (Lanuza et al., 2004). Moreover, the Dbx1 lineage includes many dorsal horn neurons as this transcription factor is also expressed in dorsal domains. Loss of $\mathrm{Db} \times 1$ results in loss of $\mathrm{V} 0_{\mathrm{D}}$ and $\mathrm{V} 0_{\mathrm{V}}$ subclasses, whereas loss of Evx1 results in a loss of only the $\mathrm{V} 0 \mathrm{~V}_{\mathrm{V}}$ subclass (Moran-Rivard et al., 2001; Pierani et al., 2001; Lanuza et al., 2004). V0 and V1 classes both express $L h x 1$ and $L h x 5$, markers of inhibitory spinal interneurons (Pillai et al., 2007).

\section{V0 Birth and Early Development}

In mouse, the majority of $D b x 1^{+}$progenitors appear between E10 and $\mathrm{E} 13$ and give rise to $\mathrm{V} 0_{\mathrm{D}}$ and $\mathrm{V} 0_{\mathrm{V}}$ commissural interneurons (Moran-Rivard et al., 2001; Pierani et al., 2001; Lanuza et al., 2004). Dbx1/2 expression is found in the rostral CNS at stage 13 in chick and more caudally by stage 15 (Pierani et al., 1999). Evx1/2 positive V0 cells are generated at stages 17 and 18 and appear in the ventral domain of $D b x 1$ and $D b \times 2$ expression (Pierani et al., 1999). Ventral Evx1/2 expressing V0 neurons appear at stages 1718 within the ventral expression domain of $D b \times 1$ and $D b \times 2$, and then migrate ventrally (Pierani et al., 1999). The V0 class appears from a $\mathrm{Pax}^{+}, \mathrm{Db} \times 1 / 2^{+}, \mathrm{Pax} 3 / 7^{-}$domain that is the dorsal-most ventral progenitor domain (Pierani et al., 1999).

\section{Vo Interneuron Subtypes vov}

The primarily inhibitory $\mathrm{V}_{\mathrm{V}}$ class is distinguished by transient expression of the homeodomain transcription factor, Evx1. These cells arise from the ventral portion of the $D b x 1^{+}$progenitor domain, and like all post-mitotic cells arising from $D b x 1^{+}$ 


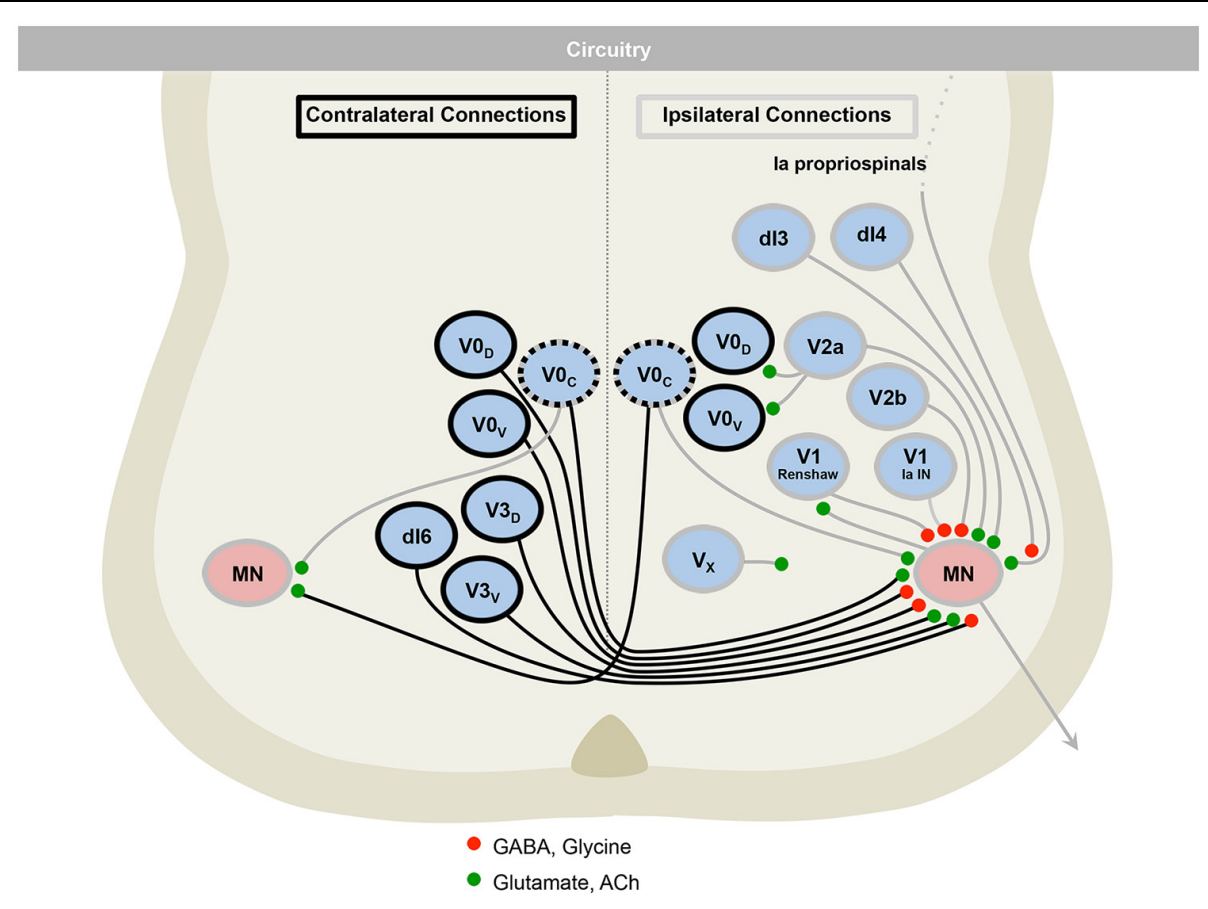

FIGURE 5 | The motor circuitry is shown in diagrammatic form in the lower panel. Here, neurons can be divided by projection patterns, that are ipsilateral, contralateral, or both. Three classes of neurotransmitter are found in the cord: excitatory glutamatergic (e.g.
V2a), inhibitory GABAergic/glycinergic (e.g., V2b), and excitatory cholinergic neurons (e.g., motor neurons). Roles for neurons in defining rate (e.g., V1), left-right alternation (e.g., V0) and rhythmicity (e.g., V3), are emerging. Adapted from Alaynick et al. (2011). progenitors, they share a similar post-mitotic migration and commissural axon pattern (Moran-Rivard et al., 2001; Pierani et al., 2001). The $\mathrm{V0V}$ interneurons are implicated in locomotion as indicated by increased c-fos immunoreactivity following fictive locomotion (Lanuza et al., 2004). However, Evx1 knockout mice have grossly normal locomotion patterns despite a $\sim 70 \%$ reduction in the $\mathrm{V}_{\mathrm{V}}$ interneurons and loss of appropriate contralateral intersegmental axonal projections in the remaining $\sim 30 \%$ of interneurons (Moran-Rivard et al., 2001). A subset of the $\mathrm{VO}_{\mathrm{V}}$ class has been reported to be excitatory in an unpublished observation (Zhang et al., 2008).

\section{V $0_{D}$}

Unlike the $\mathrm{V} O \mathrm{~V}_{\mathrm{V}}$ subclass, the more dorsal $D b x 1^{+}$progenitors of the glycinergic/GABAergic $\mathrm{V} 0_{\mathrm{D}}$ class do not express Evx1 (Pierani et al., 2001; Lanuza et al., 2004). And while both $\mathrm{V}_{\mathrm{D}}$ and $\mathrm{V} 0 \mathrm{~V}$ classes have similar axon guidance and cell body position, the loss of the $\mathrm{V}_{\mathrm{D}}$ class, in conjunction with $\mathrm{V} 0_{\mathrm{V}}$ class, does appear to alter locomotor behavior. When $D b \times 1$ is knocked out, eliminating all V0 progenitors, a disruption of left-right coordination is observed at lumbar levels L2 and L5. These periods of left-right synchrony are intermittent and periods of normal left-right alternation are observed amidst episodes of synchrony (Lanuza et al., 2004). No disruption of flexorextensor behavior, as indicated by alternating phasic activity of the L2 and L5 segments, was observed in a drug-induced isolated cord fictive locomotion assay (Lanuza et al., 2004). Recently, studies have showed that a cluster of $\mathrm{V}_{\mathrm{D}}$ cells lateral to the central canal receive substantial input from primary afferents and preferentially project axons toward contralateral motoneurons via an oligosynaptic pathway, and are active during fictive locomotion. This suggests that this subset of V0 interneurons may be primarily responsible for coordination of left-right alternation during locomotion (Griener et al., 2015).

\section{$\mathrm{V} 0_{\mathrm{C}}$ and $\mathrm{V} \mathrm{O}_{\mathrm{G}}$}

The $\mathrm{V} 0_{\mathrm{C}}$ and $\mathrm{V} 0_{\mathrm{G}}$ subclass represent $\sim 5 \%$ of $\mathrm{V} 0$ progenitors and are identified by expression of Pitx2 and occupy a medial position dorsal to the central canal (Zagoraiou et al., 2009). These cells were first observed in lumbar levels at E11.5-12.0 by Pitx2 immunoreactivity which, unlike many embryonic markers, could be detected until postnatal day 30 (Zagoraiou et al., 2009). Neurotransmitter markers can subdivide the Pitx $2^{+}$cells into cholinergic $\left(v A C h T^{+}\right.$and $\left.\mathrm{ChAT}^{+}\right)$and glutamatergic $\left(v G l u T 2^{+}\right)$ types that are distinct (Zagoraiou et al., 2009). While these are found at cervical and lumbar levels, within the lumbar cord, these two types are distributed in a gradient such that a greater number of cholinergic interneurons are found at more rostral levels and a greater number of glutamatergic interneurons at more caudal levels (Zagoraiou et al., 2009). The cholinergic cells are distinct from Pitx ${ }^{-}$cholinergic $\mathrm{C}_{3}$ propriospinal interneurons (Zagoraiou et al., 2009). By genetic tracing, $\sim 80 \%$ of these neurons were determined to be from a $D b x 1^{+}$progenitor domain at E12.5 and loss of $D b x 1$ eliminated the Pitx2 immunoreactivity in the intermediate cord. Because $\mathrm{V} 0_{\mathrm{C}}$ and $\mathrm{V}_{\mathrm{G}}$ Pit $x 2^{+}$cells transiently express Evx1, they appear to be subsets of the $\mathrm{V} 0 \mathrm{~V}$ 
class. This relatively small ipsilaterally and bilaterally projecting class, however, is responsible for perhaps all c-boutons on motor neurons found in P8 to P25 mice (Zagoraiou et al., 2009; Stepien et al., 2010). These interneurons provide relatively weak innervation to Sox14::eGFP ${ }^{+} \mathrm{V} 2 \mathrm{a}$ and calbindin ${ }^{+} \mathrm{V} 1$ Renshaw cells. These cells appear to be involved in local circuitry as corticospinal and sensory $v G l u T 1^{+}$glutamatergic boutons were not found, whereas serotonergic and GAD67 ${ }^{+}$GABAergic boutons were observed (Zagoraiou et al., 2009). While previous experiments did not find a gross locomotor behavioral defect with loss of the $\mathrm{V} 0 \mathrm{~V}_{\mathrm{V}}$ subclass in Evx1 mutant animals, Pitx2 mutant animals were found to have defects in locomotion revealed by EMG recordings during swimming (Zagoraiou et al., 2009). This deficit was argued to represent an abnormal integration of sensory inputs. It may, alternatively or in addition, represent a deficit in C-terminal modulation of motor neuron excitability. A survey in E12.5 mice showed that several V0 subclasses can be defined by expression of Pax2, Pax6, Evx1, Ptx2, Nurr1, HNF-6, BhlhB5, and Prdm8 (Francius et al., 2013).

\section{V1 Interneuron Characteristics}

As a population, this group appears to control burst durations and is comprised of cells physiologists defined as Ia inhibitory and Renshaw cells. Mice models without V1 and V2b showed significant difficulty with limb articulation in flexion and extension (Zhang et al., 2014). The $\mathrm{pV} 1$ progenitor domain gives rise to important inhibitory subclasses of neurons that were previously described electrophysiologically: the Ia inhibitory interneurons that mediate reciprocal inhibition and the Renshaw cells that mediate inhibitory feedback to integrate limb and muscle length information into spinal circuitry. Renshaw cells and Ia inhibitory interneurons are V1 derived, but differ in morphology, location, calcium-binding protein expression, synaptic connectivity, and function. These differences are already present in neonates and their differentiation starts in the early embryo (Benito-Gonzalez and Alvarez, 2012). In addition, $75 \%$ of V1 interneurons are non-Ia, non-Renshaw subclasses that await characterization (Sapir et al., 2004; Alvarez et al., 2005). Short-range ipsilaterally and rostrally projecting glycinergic/GABAergic V1 neurons are characterized by transient expression of homeodomain transcription factor En1 (Figure 4C; Burrill et al., 1997; Matise and Joyner, 1997; Pierani et al., 1999, 2001; Saueressig et al., 1999). Studies in embryonic chick indicate that these neurons project for only 1-2 segments and have been shown to make inhibitory contacts onto motor neurons and other interneurons, although this may not be the case in the mature mouse (Wenner et al., 1998, 2000). Loss of Pax6 or En1-dependent DTA ablation eliminates the recurrent inhibition by Renshaw cells on motor neurons (Sapir et al., 2004; Gosgnach et al., 2006). Elimination of V1 interneurons results in a marked slowing on the drug-induced fictive locomotion period that is seen in conventional knockouts, targeted ablation, and acute inhibition with allatostatin (Gosgnach et al., 2006; Goulding, 2009). The mechanism by which elimination of an inhibitory class would prolong the locomotor cycle remains unknown and may result from the loss of inhibitory neurons to terminate $\mathrm{MN}$ firing. The V1 class, like V0, expresses the inhibitory spinal interneuron markers $\operatorname{Lh} x 1$ and $\operatorname{Lh} x 5$ (Pillai et al., 2007).

\section{V1 Birth and Early Development}

Unlike cells in the dorsal-most p0 domain that expresses $D b x 1$ and $D b x 2$, the adjacent $\mathrm{p} 1$ domain only expresses $D b \times 2$ (Pierani et al., 1999). The V1 class appears from a $\mathrm{Pax}^{+}, \mathrm{Db} \times 2^{+}$, $N k x 6.2^{+}, D b x 1^{-}$domain that is ventral to the $D b \times 1 / 2^{+}$V0 domain (Matise and Joyner, 1997; Pierani et al., 1999). In chick, $E n 1^{+}, \operatorname{Lim} 1 / 2^{+} \mathrm{V} 1$ neurons appear at stage 17, and most appear ventral to the domain of $D b x 1$ expression, within the ventral domain of these $D b x 2^{+}, D b x 1^{-}$progenitors (Pierani et al., 1999). $D b x$ expression does not overlap with En1, perhaps due to the relatively late expression of En1 (Pierani et al., 1999). Genetic tracing studies using $D b x 1^{\text {nlsLacZ }}$ mice between ages E10 and E16.5 found that $\sim 5-10 \%$ of $E n 1^{+}$cells did express a low level of $\beta$ gal, perhaps a reflection of transient $D b x 1$ expression and more enduring $\beta$ gal protein. The V1 class is marked by expression of Foxd3, found in the dI2 domain, as well (Ramos et al., 2010). The transcription factor, Bhlhb5, which marks the V1, V2 and dI6 domains, is required at least partially for V1 identity assessed by En1 expression (Ramos et al., 2010; Skaggs et al., 2011). Expression of Bhlhb5 in conjunction with Ngn2 facilitates V1 identity ectopically (Skaggs et al., 2011).

\section{V1 Interneuron Subtypes V1 Renshaw}

Renshaw cells use both glycine and GABA as neurotransmitters, transiently express Gad65 early in embryonic development and have both motor neurons and Ia interneurons as targets (Saueressig et al., 1999; Sapir et al., 2004). They also express calbindin D28K embryonically and continue to express this marker into adulthood (Alvarez et al., 1999; Geiman et al., 2000). They receive input from motor neuron collaterals that release acetylcholine, glutamate, and aspartate (Mentis et al., 2005; Richards et al., 2014). Renshaw cells modulate proprioceptive sensory input and motor neuron output. Genetic tracing studies showed that Renshaw cells are derived from an $E n 1^{+}$progenitor pool and, although they are not lost in the absence of En1, they do have fewer motor neuron recurrent inputs (Sapir et al., 2004). They are, however, lost in the absence of Pax6 (Sapir et al., 2004). Recent study showed that selective activation of the Onecut transcription factors Oc1 and Oc2 during the first wave of $\mathrm{V} 1$ interneuron neurogenesis is a key step in the Renshaw cell differentiation; furthermore Renshaw cell development is dependent on the forkhead transcription factor Foxd3, which is more broadly expressed in post-mitotic V1 interneurons (Stam et al., 2012).

\section{V1 la Interneuron}

Although Ia interneurons have been rediscovered as a V1 subclass, like Renshaw cells, the Ia INs were functionally described before the advent of molecular genetic dissection of interneuron development (Eccles et al., 1954; Hultborn et al., 1971; Hultborn and Udo, 1972) These inhibitory glycinergic cells receive input from muscle spindle Ia proprioceptive afferents carrying muscle length information and provide inhibitory 
input onto motor neurons innervating antagonist muscles. Like motor neurons, Ia receive inhibitory inputs from Renshaw cells (Hultborn et al., 1971). In neonatal mice, disynaptic glycinergic reciprocal inhibition is mediated by Ia interneurons, although this activity is preserved in the absence of Pax6, indicating that cells of more than one origin contributes to this functional class (Wang et al., 2008). Only when V1 and V2b are both ablated is reciprocal inhibition profoundly altered. Renshaw cells constitute $8-19 \%$ of V1 interneurons and the Foxp2 $2^{+}$ (by immunohistochemistry) population accounts for around $33 \%$ of these neurons at P0 and $50 \%$ at E13 (Morikawa et al., 2009). Because there are no universal markers of Ia interneurons, all Ia interneurons cannot be accounted for, leaving the physiologic properties and connectivity patterns of V1 interneurons unaccounted for (Alvarez et al., 2005). Of note, some interneurons with synaptic organization like Ia interneurons have been found that arise from the V1 population and are Foxp2 positive (Morikawa et al., 2009). A survey in E12.5 mice showed that several V1 subclasses can be defined by expression of Calbindin, OC1, OC2, OC3, Foxd3, En1, MafB, FoxP2, Foxd3, Foxp4, Pax2, Arx, Evx1, Nurr1, BhlhB5, Pou4F1, Pou3F1, and Prdm8 (Francius et al., 2013).

\section{V2 Interneuron Characteristics}

$\mathrm{V} 2$ interneurons become divided into V2a and V2b classes of ipsilaterally projecting interneurons that extend axons caudally across several segments (Goulding, 2009). The excitatory V2a class is glutamatergic and expresses Chx10, while the Gata2/3 ${ }^{+}$ $\mathrm{V} 2 \mathrm{~b}$ class is inhibitory and uses both glycine and GABA (Figure 4D; Al-Mosawie et al., 2007; Lundfald et al., 2007). The transcription factor, Bhlhb5, marks the V2, as well as V1 and dI6 domains (Ramos et al., 2010).

\section{V2 Birth and Early Development (Notch-Delta)}

V2 interneurons arise from a progenitor pool just dorsal to the pMN domain and share expression of $L h \times 3$ with the pMN domain. In addition, both domains share expression of NLI that forms homodimers. This NLI homodimer nucleates the formation of a higher-order tetramer with Lhx3 in the V2 progenitor domain, and in the case of pMNs this V2defining tetramer (Lhx3-NLI-NLI-Lhx3) is disrupted by the insertion of Isl1 to form a hexamer (Lhx3-Isl1-NLI-NLI-Isl1Lhx3). Transcriptional response elements that are active in V2 cells can bind both the motor neuron hexamers and the V2 associated tetramers, while response elements active in motor neurons are only responsive to the hexamers (Lee et al., 2008). Later the V2 domain expresses Chx10 that acts as a repressor of motor neuron associated hexamers in V2 progenitors, leaving only the LIM tetramers active (Sander et al., 2000; Lee et al., 2008). The progenitor pool of V2 neurons becomes post-mitotically segregated into V2a and V2b neurons.

Time-lapse imaging in zebrafish showed that the majority of V2 progenitors give rise to a pair of V2a and V2b cells (Kimura et al., 2008), indicating that V2a and V2b arise from the same progenitor. This segregation into V2a and V2b is mediated by Notch/delta signaling in zebrafish and mouse models (Yang et al., 2006; Del Barrio et al., 2007; Peng et al., 2007). In mouse, Delta4, but not Delta 1, activates this signaling cascade and is downstream of Foxn4, which also induces expression of Mash1/Ascl1 (Del Barrio et al., 2007; Peng et al., 2007). Mind bomb-1 (Mib1) is an E3 ubiquitin ligase that ubiquitinates and promotes the endocytosis of Notch ligands. In mice model, Mib1 plays an important role in Notch activity and specific differentiation, neurogenesis and gliogenesis of V2 interneurons. Mice models with abnormal Mib1 resulted in unclear spinal progenitors, premature or unbalanced differentiation or loss of astrocytes and oligodendrocytes (Kang et al., 2013). In zebrafish embryos two ligands, DeltaA and DeltaD, and three receptors, Notch1a, Notch1b, and Notch3 redundantly contribute to $\mathrm{p} 2$ progenitor maintenance; on the other hand, DeltaA, DeltaC, and Notch1a mainly contribute to the V2a/V2b cell fate determination (Okigawa et al., 2014). Misra et al. (2009) showed Foxn4 and proneural factors may serve as the trigger to initiate asymmetric Dll4-Notch and subsequent BMP/TGF $\beta$ signaling events required for neuronal diversity in the V2 domain (Okigawa et al., 2014). V2b fate is specified by active Notch1, Foxn4, Mash1, and $\mathrm{Scl}$ Notch-binding protein MAML is also required for this specification (Peng et al., 2007). Lack of active Notch1 results in V2a fate, shown in an increase of V2a interneurons at the expense of V2b in Psn $1 \mathrm{KO}$ mice or Notch1 KO mice (Del Barrio et al., 2007; Peng et al., 2007). Transcription factor Gata2 is necessary in the normal development of V2a and V2b neurons and Gata2 promotes the selective activation of V2b at the expense of V2a fate (Francius et al., 2014). Progenitors that express the notch ligand, Delta-like 4 generate almost all V2a and V2c neurons while producing only a small fraction of neurons of other subtypes along the dorsoventral axis (Zou et al., 2015).

\section{V2 Interneuron Subtypes V2a Sox $14 / \mathrm{Ch} \times 10$}

The V2a class of ipsilaterally projecting interneurons expresses the transcription factors Chx10 and Sox14 and is glutamatergic. These interneurons are composed of cells with diverse firing properties and morphologies with local as well as long-range ipsilateral projection patterns (Dougherty and Kiehn, 2010a,b; Zhong et al., 2010). This class of interneurons has been shown to contact motor neurons (Al-Mosawie et al., 2007; Stepien et al., 2010) and contralaterally projecting V0 interneurons (Crone et al., 2008). Loss of these cells has been shown to disturb locomotor function in a state-dependent manner (Crone et al., 2008, 2009; Dougherty and Kiehn, 2010a,b; Zhong et al., 2010). In a series of in vitro experiments it was found that Chx10-DTA V2a-ablated mice displayed more variable amplitude and period than wild-type controls during drug-induced fictive locomotion. Further, these mutant animals had incoherent left-right alternation during druginduced fictive locomotion. Surprisingly, these animals failed to display coordinated brainstem stimulated or dorsal root stimulated fictive locomotion, suggesting that $\mathrm{Ch} \times 10^{+}$cells mediate descending and sensory activation of locomotor activity (Crone et al., 2008).

A subsequent study, using a different strain of mice that avoided the neonatal lethality seen in previous work, showed that during treadmill running, Chx10-DTA mice can transition from 
alternating locomotion to synchronous hindlimb locomotion at higher speeds. High-speed synchronous left-right activity, or galloping, is not normally seen in mice, although it has been described in studies of Eph and ephrin signaling molecule mutant mice (Dottori et al., 1998; Kullander et al., 2001; Yokoyama et al., 2001). The Eph/ephrin mutant mice, however, have synchronous activity at both slow and fast speeds. Some V2a interneurons express EphA4, but a compelling correlation has yet to be discovered (Lundfald et al., 2007). In zebrafish, alx, a zebrafish homolog of Chx10, is expressed in an ipsilateral descending excitatory interneuron population named $\mathrm{CiD}$ (circumferential descending) neurons that monosynaptically contact motor neurons (Kimura et al., 2006; McLean et al., 2008). This population has been shown to be active during high-frequency swimming in larval zebrafish (McLean et al., 2008). Within this interneuron class, dorsally located cells are recruited at a high swimming frequency. As the frequency decreases, more ventral cells are recruited, accompanied by silencing of previously active dorsal cells (McLean et al., 2008). A survey in E12.5 mice showed that V2a subclasses can be defined by expression of BhlhB5, Pou3F1, OC1, OC2, OC3, Prdm8, MafA, and cMaf (Francius et al., 2013).

\section{V2b Gata2/3}

Ipsilaterally projecting V2b interneurons express Gata2/3, are inhibitory GABAergic neurons, and appear to make direct connections onto motor neurons (Lundfald et al., 2007; Peng et al., 2007). Observations by the Goulding lab indicate they project caudally (Zhang et al., 2014). These cells may underlie the retained reciprocal inhibitory pathways seen in V1 knockout mice (Wang et al., 2008). A survey in E12.5 mice showed that V2b subclasses can be defined by expression of BhlhB5, Pou3F1, OC1, OC2, OC3, Prdm8, MafA, and MafB (Francius et al., 2013). As pointed out earlier, V1- and V2b-derived neurons function as the core interneuronal components of the limb central pattern generator $(\mathrm{CPG})$ that coordinate flexor-extensor motor activity (Zhang et al., 2014).

\section{V2c Sox1}

The V2 interneuron class has recently been shown to further diverge to a Sox1-expressing Gata3-negative population named $\mathrm{V} 2 \mathrm{c}$ interneurons, function of which is still yet to be elucidated ( $\mathrm{Li}$ et al., 2010; Panayi et al., 2010). A survey in E12.5 mice showed that V2c subclasses can be defined by expression of Sox1, OC1, OC2, and OC3 (Francius et al., 2013).

\section{V3 Interneuron Characteristics}

The Sim1 ${ }^{+}$VGluT2 $^{+}$glutamatergic V3 interneurons send projections predominantly contralaterally and caudally (Goulding, 2009). Genetic tracing, using a Sim1-eGFP or Sim $1^{\text {Cre }}$ and reporter lines, and viral tracing, using pseudorabies, shows that $80-85 \%$ of these cells project contralaterally and a minor proportion remain ipsilateral or project both contra- and ipsilaterally (Zhang et al., 2008). As a population, Sim1 $1^{+} \mathrm{V} 3$ interneurons form $24 \%$ of glutamatergic connections on V1 Ia, $27 \%$ on Renshaw subclasses, $22 \%$ of glutamatergic synapses on lateral motor column motor neurons, as well as connections on $\operatorname{Lh} \times 3^{+} \mathrm{V} 2$ interneurons, and lamina VIII commissural interneurons (Zhang et al., 2008). Behaviorally, loss of V3 neuronal activity by genetic attenuation with tetanus toxin or allatostatin signaling resulted in a loss of CPG robustness. In isolated cord fictive locomotion, both dorsal root stimulation and drug-induced methods produced weak CPG activity in only some of the cords examined. The outputs were less consistent and had greater coefficients of variance. Although both right and left sides of the cord produced irregular outputs, the fidelity of left-right coordination was preserved suggesting that V3 interneurons do not regulate the coordination of left-right activity. In adult Sim1 ${ }^{\text {Cre }}$ AlstR192 animals, application of allatostatin to the cord produced locomotor disturbances in gait, as well (Zhang et al., 2008). In Sim1 mutant mice, V3 interneurons are produced normally and maintain in the similar position and organizations as wild-type; however, there is significant reduction of interneurons in dorsal subgroup and there is significant reduction in the contralateral axonal projection. Therefore, Sim 1 appears to be critical in migration and axonal projection of V3 interneuronal development (Blacklaws et al., 2015). Mice that are mutant for $N k \times 2.2$ and $N k x 2.9$ lose V3 interneurons and $N k \times 2.2^{+/-} N k x^{-/-}$mice display intermittent or permanent hopping gait ( $\mathrm{Holz}$ et al., 2010). Holz et al. (2010) indicate that this mutation affects floor plate, and therefore likely affects commissural interneuron projections that mediate left-right coordination. A survey in E12.5 mice showed that V2c subclasses can be defined by expression of Olig3, Prox1, BhlhB5, and Nurr1 (Francius et al., 2013).

\section{V3 Birth and Early Development}

These V 3 interneurons arise from the ventral-most $\mathrm{p} 3$ progenitor domain defined by homeobox transcription factors $N k x 2.2$ and $N k \times 2.9$ and the PAS-bHLH transcription factor Sim1 (simple-minded homolog 1; Figure 4E; Briscoe et al., 1999; Goulding et al., 2002). Genetic tracing techniques using a $\operatorname{Sim} 1^{\text {TauLacZ }}$ knock-in reporter mouse or Sim $1^{\mathrm{Cre}}$ and reporter

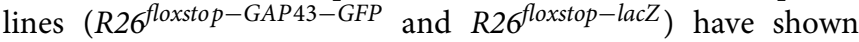
similar expression at E11.5 to in situ hybridization data for Sim1 expression that appeared just lateral to the $N k x 2.2$ progenitors (Marion et al., 2005; Zhang et al., 2008). Nkx2.2 also regulates the expression of Olig3 in V3 neurons. While Olig3 plays a key role in respecification of $\mathrm{dl} 2$ and $\mathrm{dl} 3$ neurons into $\mathrm{dl} 4$ interneurons in dorsal spinal cord (see below), it does not appear to affect the generation and migration of the ventral neurons (Liu et al., 2014).

\section{$\mathrm{V} 3_{\mathrm{D}}$ and $\mathrm{V} 3_{\mathrm{V}}$}

Each class of interneurons can likely be further subdivided. The existence of V3 subtype heterogeneity defined by cell body positions was first reported in a review of locomotor circuitry by the Goulding group (Goulding, 2009). This group recently examined both electrophysiological and morphological properties of mature V3 interneurons in adult mouse and were able to identify two V3 subpopulations with distinct intrinsic properties and distributions (ventral and dorsal), as well as an important intermediate subgroup (Borowska et al., 2013). They 
reported $\mathrm{V} 3_{\mathrm{V}}$, primarily located in lamina VIII, possessed a few branching processes and were capable of generating rapid tonic firing spikes and $\mathrm{V}^{\mathrm{D}}$ had a more complex morphology with relatively slow average spike frequency with strong adaptation (Borowska et al., 2013). A survey in E12.5 mice showed that V3V express Olig3, Prox1, BhlhB5, and Nurr1, and V3D can be defined by expression of OC1, OC2, and OC3 (Francius et al., 2013).

\section{$\mathrm{V}_{\mathrm{X}} \mathrm{Hb} 9$}

A group of glutamatergic, rhythmically active interneurons with possible connections to motor neurons can be found along either side of the ventral midline in thoracic and upper lumbar segments (Thaler et al., 1999; Wichterle et al., 2002; Hinckley et al., 2005; Wilson et al., 2005). These $\mathrm{Hb}^{+}$and VGluT2 ${ }^{+}$interneurons are found in lamina VIII, although the developmental origin of these cells is unknown (Figure 4F). These cells have oscillatory behavior, make potential contacts with motor neurons, and are associated with motor rhythms (Hinckley et al., 2005; Wilson et al., 2005; Hinckley and Ziskind-Conhaim, 2006). These interneurons were the first to show oscillatory properties and efforts have been made to discover a relationship to rhythm generation or a pacemaker property for the CPG (Kwan et al., 2009). No cell class, however, has been found to act as a pacemaker for CPG activity. Remaining questions for the $V_{X}$ include: what is the progenitor domain that gives rise to the $V_{X}$ domain; and why are they not found below the L2 segment at E18.5.

\section{Dorsal Interneuron Progenitors}

There are eight canonical classes of dorsal progenitors, dI1-6 and $\mathrm{dIL}_{\mathrm{A}}$ and $\mathrm{dIL}_{\mathrm{B}}$. Of these, the dorsal-most dI1-3 progenitors are dependent on signals from the roof plate and termed Class A (Liem et al., 1997; Lee et al., 2000). The remaining dI4-6 and $\mathrm{dIL}_{\mathrm{A}}$ and $\mathrm{dIL}_{\mathrm{B}}$ are independent of roof plate signals and termed Class B (Gross et al., 2002; Muller et al., 2002). The dorsalmost progenitors, pd1-pd3, are born between days E9.5 and 10.5 and become post-mitotic and begin to migrate ventrally between E10.5 and E11.5 (Helms and Johnson, 1998; Bermingham et al., 2001; Gross et al., 2002; Muller et al., 2002). These cells will eventually form the deeper layers of the dorsal horn. The more ventral Class B dI4-6 cells are born between E10 and 12.5 and then post-mitotically express $L b x 1$ and migrate either dorsally to form the more superficial layers of the dorsal horn or migrate ventrally to the deep dorsal horn and the ventral spinal cord (Gross et al., 2002; Muller et al., 2002). The later born $\mathrm{dIL}_{\mathrm{A}}$ and $\mathrm{dIL}_{\mathrm{B}}$ classes are born between E11 and E13 and are intermixed with each other. They then migrate dorsally and constitute a significant portion of the cells in the superficial dorsal horn, including the substantia gelatinosa (Nornes and Carry, 1978; Gross et al., 2002; Muller et al., 2002; Mizuguchi et al., 2006). As with the ventral interneuron classes, each of these classes, or their subgroups, has characteristic features. For instance, each interneuron subclass appears to have a unique axonal projection that produces a tight fascicle within white matter tracts (Avraham et al., 2009, 2010).

\section{dl1 Interneuron Characteristics}

The dorsal-most progenitor domain pd1 expresses the bHLH transcription factor $\mathrm{Math}^{+}$(Mouse atonal homolog 1, also known as Atoh1) and gives rise to at least two VGluT2 ${ }^{+}$ glutamatergic subclasses: $\mathrm{dI} 1 \mathrm{~A}$ and $\mathrm{dI} 1 \mathrm{~B}$, characterized by Lim-HD expression and their spinocerebellar tract (SCT) contributions (Figure 4G). Recent study shows that Msx1 and $M s x 2$, two homeodomain transcription factors that are induced earlier than bHLH transcription factors, likely play a role as transcriptional activators of Math1/Atoh1 in spinal cord development (Duval et al., 2014). The dI1A (also known as $\mathrm{dI} 1_{\text {comm }}$ ) neurons express the Lim-HD transcription factors Lhx $2_{\text {high }}$ and $L h x 9_{\text {low }}$, while dI1B (also known as $\mathrm{dI} 1_{\text {ipsi }}$ ) express the Lim-HD TF Lhx9 (Helms and Johnson, 1998; Lee et al., 1998; Bermingham et al., 2001; Gowan et al., 2001; Wilson et al., 2008; Avraham et al., 2009). The dI1 interneurons migrate to the deep dorsal horn and intermediate gray where they receive proprioceptive input from the periphery and form commissural projections of dorsal and ventral SCTs (Helms and Johnson, 1998; Bermingham et al., 2001). Using an Atoh $1^{\text {LacZ }}$ allele to trace the fate of pd1 progenitors in developing mouse, at least two subsets of the dI1 class have been identified: (1) a medial cluster of vertically oriented neurons that are $C b \ln 2^{+}$and $S m a r c a 2^{+}$and projects to the SCT in the contralateral $\left(\mathrm{Tag} 1^{+}\right)$lateral funiculus; (2) a more lateral Sox $6^{+}$, cluster of horizontally oriented neurons that contributes to the SCT in the ipsilateral lateral funiculus (Miesegaes et al., 2009). In chick, data with an enhancer that labels these cells suggests that both fascicles coalesce in the lateral funiculus ventral to the fascicle formed by the $\mathrm{dI} 2$ projections (Avraham et al., 2009).

\section{dl1 Birth and Early Development}

The roof-plate-dependent Class A dp1 progenitors of the dI1 class express the bHLH transcription factors Olig3 and Math1 (Muller et al., 2005; Gowan et al., 2001). The dI1 neurons in mouse are born between E10 and E12.5 and express Lhx2/9, Barhl1 (bar homeobox like 1) and Brn3a (Pou4f1, a class IV POU domaincontaining transcription factor; Helms and Johnson, 1998). Loss of function experiments with BMP7 in chick and Bmp7 mutant mice results in loss of dI1, dI3, and dI5 (Le Dréau et al., 2012).

\section{dl2 Interneuron Characteristics}

$\mathrm{dI} 2$ interneurons are ascending, contralaterally projecting, relay interneurons that migrate to the intermediate spinal cord and ventral horn (Gowan et al., 2001; Gross et al., 2002). These interneurons have been suggested to convey sensory information via the spinothalamic tract to the thalamus, based on their location (Figure 4E; Brown, 1981; Tracey, 1985; Gross et al., 2002). The projections likely occupy the lateral funiculus and are dorsal to the dI1 fascicle, as analyzed by enhancer expression in chick (Avraham et al., 2009). Arising from bHLH transcription factor Ngn1 (neurogenin 1) and Ngn2 expressing progenitors, these neurons express LIM-HD transcription factors $L h x 1, L h \times 5$ and winged-helix domain Foxd3 (forkhead homeobox D3) postmitotically (Bermingham et al., 2001; Gowan et al., 2001; Gross et al., 2002). These interneurons were previously known as D3A interneurons. 


\section{dl2 Birth and Early Development}

The roof-plate-dependent Class A dI2 progenitor domain, pd2, is characterized by the expression of the bHLH transcription factors, Olig3, Ngn1, and Ngn2 and are born between E10- and E12.5 (Figure 4H; Gowan et al., 2001; Muller et al., 2005). Two SoxD transcription factors, Sox5 and Sox6, are expressed in restricted domains of dorsal progenitors. Sox 5 controls cell fate specification of $\mathrm{dp} 2$ and $\mathrm{dp} 3$ progenitors and, as a result, controls the correct number of the corresponding dorsal interneurons (dI2 and dI3; Quiroga et al., 2015).

\section{dl3 Interneuron Characteristics}

The dI3 neurons are excitatory interneurons in the deep dorsal horn and intermediate spinal cord (Liem et al., 1997; Gowan et al., 2001; Cheng et al., 2004). These cells target motor neurons monosynaptically, as revealed by recent rabies tracing experiments (Stepien et al., 2010). They have axons that project rostrally, ipsilaterally, and longitudinally in two fascicles. A ventral fascicle enters the ventral lateral funiculus (VLF) and the dorsal fascicle enters the dorsal funiculus (DF; Avraham et al., 2010). The dorsal projecting axons re-enter the cord when they encounter axons sensory axons at the dorsal root entry zone (DREZ; Avraham et al., 2010). Similarly, the ventrally projecting neurons re-enter the cord at ventral root exit points (Avraham et al., 2010). In mice model, dl3 appears to convey input from low threshold cutaneous afferents to the motor neurons that is critical in hand/forelimb grip (Bui et al., 2013). The dI3 pool also expresses Tlx3 (T-cell leukemia homeobox 3) and LIMHD transcription factor Isl1-expressing cells (Figure 4I; Gross et al., 2002). The turning behavior of dI3 neurons is dependent on Isl1, and expression of Isl1 in dI1 neurons conferred dI3like axon choice points to dI1 neurons (Avraham et al., 2010). Tlx1 (also known as Hox11) and Tlx3 (also known as Rnx and Hox11L2) are markers of glutamatergic signaling. Tlx 3 functions cell-autonomously to specify a glutamatergic neurotransmitter phenotype (Cheng et al., 2004).

\section{dI3 Birth and Early Development}

The roof-plate dependent Class A dP3 progenitors express the basic helix-loop-helix (bHLH) transcription factor Mash1 (Ascl1, Mouse Achaete-scute complex-like 1), as do adjacent pd4 and pd5 domains (Gowan et al., 2001; Helms et al., 2005). They also express Olig3, Pax7 and Ngn2 and Gsh2 (Muller et al., 2005). In chick spinal cord electroporation experiments it has been shown that over-expression of Olig 3 increases dI 3 interneurons at the expense of other Classes A and B neuron classes and this effect is enhanced by Mash1 (Muller et al., 2005). Overexpression of Mash1 results in more dI3 and dI5 neurons at the expense of dI2 and dI4 (Muller et al., 2005), while loss of Mash1 causes a decrease in $\mathrm{dI} 3$ and dI5 populations while dI4 is maintained (Helms et al., 2005). As mentioned above, loss of function experiments with BMP7 in chick and Bmp7 mutant mice results in loss of dI1, dI3, and dI5 (Le Dréau et al., 2012).

\section{dl4 Interneuron Characteristics}

The early born (E10.5-E11) dI4 interneurons become Pax2 ${ }^{+}$, $L h x 1^{+}$, and $L h x 5^{+}$GABAergic ipsilaterally projecting somatosensory associative neurons that migrate laterally to the deep dorsal horn (Figure 4J; Gross et al., 2002; Muller et al., 2002; Pillai et al., 2007). In addition, both dI4 and dI5 interneurons also express Gsh1 (Gsx1) and Gsh2 post-mitotically, while dI3 only express Gsh2 (Kriks et al., 2005; Muller et al., 2005; Mizuguchi et al., 2006). They are GABAergic, calbindin ${ }^{+}$and express the nociceptive marker PLC $\gamma$ (Chen et al., 2001; Helms and Johnson, 2003). The dI4 fate is dependent on Ptf1a and loss of this gene results in loss of all GABAergic dorsal neurons and respecification to dI5 fate (Henke et al., 2009; Meredith et al., 2009). Loss of Lhx1 and Lhx5 results in a loss of Pax2, Viaat, and Gad1 (Pillai et al., 2007). In addition, Pax2 is required for the maintained expression of Lhx1, Lhx5, Pax5, and Pax8 (Pillai et al., 2007).

\section{d14 Birth and Early Development}

The roof-plate independent Class B dP4 domain expresses $L b x 1$, Mash1 and higher levels of Pax7 than the dorsally adjacent pD3 domain (Gross et al., 2002; Muller et al., 2002). These progenitors are born between E10.5 and E11 and this domain is distinct from the dIL progenitor domain that produces $\mathrm{dIL}_{\mathrm{A}}$ and $\mathrm{dIL}_{\mathrm{B}}$ progenitors, although both have very similar transcription factor expression patterns (below). Olig3 over-expression can inhibit formation of dI4, and loss can result in expansion of this domain (Muller et al., 2005). While these cells express Mash1, loss of Mash 1 does not block dI4 formation, yet it does disrupt dI 3 and dI5 (Helms et al., 2005).

\section{dl5 Interneuron Characteristics}

The roof-plate independent Class B dI5 neurons become contralaterally projecting glutamatergic somatosensory interneurons of the deep dorsal horn (nucleus proprius) and ventral horn that express the homeodomain transcription factors $L b x 1, B r n 3 a, T l x 1, T l x 3$, and $L m x 1 b$ (Figure 4K; Gross et al., 2002; Muller et al., 2002; Qian et al., 2002; Ding et al., 2005; Glasgow et al., 2005). In addition, a subset expresses PhoxA2 (Ding et al., 2004). These interneurons were previously known as D4.

\section{dI5 Birth and Early Development}

These cells are born between E10.5-E11 and arise from a Mash $1^{+}$ and $\mathrm{Pax}^{+} \mathrm{dP} 5$ progenitor domain that express $L b \times 1$ postmitotically to both reinforce Class B fate and oppose Class A fates (Figure 4K; Gross et al., 2002; Muller et al., 2002). The dI5 domain expresses Gsh1 and Gsh2, as does the adjacent dI4 domain (Kriks et al., 2005). As noted previously, loss of function experiments with BMP7 in chick and $B m p 7$ mutant mice results in loss of dI1, dI3, and dI5 (Le Dréau et al., 2012).

\section{dl6 Interneuron Characteristics}

The roof-plate independent Class B dI6 commissural inhibitory interneurons express $L b x 1, L h x 1, L h x 5$, and are Pax2 positive, indicating a GABAergic fate (Figure 4L; Gross et al., 2002; Muller et al., 2002; Cheng et al., 2004; Glasgow et al., 2005; Pillai et al., 2007). These cells may also use glycine for neurotransmission (Goulding, 2009). Although arising from a dorsal progenitor pool, and not being part of the "V" interneurons, the dI6 group 
of interneurons gives rise to more than one subtype and appears to contribute to motor function (Gross et al., 2002; Muller et al., 2002; Lanuza et al., 2004). These inhibitory neurons are reported in unpublished observations to be commissural and may be involved in right-left alternation, as well (Goulding, 2009). Dmrt3, a novel marker in dl6 interneuron was traced to play a key role in locomotor circuitry and in development of commissural interneurons, and mutation in dmrt3 result in divergent in gait pattern in mice models (Andersson et al., 2012; Vallstedt and Kullander, 2013). Double knockout of Lhx1 and Lhx5 results in a loss of Pax2, Viaat, and Gad1 expression (Pillai et al., 2007). Furthermore, Pax2 is required for the maintained expression of Lhx1, Lhx5, Pax5, and Pax8 (Pillai et al., 2007). These cells also express WT1 (Wilms' tumor 1; Goulding, 2009). The transcription factor, Bhlhb5, marks the dI6, V1 and V2 domains (Ramos et al., 2010). Electrophysiologic characteristics of the dl6 interneurons around a central canal reveal two possible subtypes: one firing trains of action potentials that are loosely coupled to the ventral root output and expressing intrinsic rhythmic activity which suggests a role in locomotor rhythm generation. The other subtype fires action potentials that are tightly coupled to the ventral root output (Dyck et al., 2012).

\section{dl6 Birth and Early Development}

The dI6 neurons are born around E10.5-E11 and originate from a $\mathrm{Pax}^{+}, \mathrm{Db} \times 2^{+}, \mathrm{Ngn}^{+}$and $\mathrm{Ngn} 2^{+}$pD6 progenitor domain. Postmitotically they express Bhlhb5, Wt1, Lbx1, Lhx1, Lhx5, and Pax2 (references above).

\section{Late Born Dorsal Interneurons}

The dIL neurons represent a second wave of neurogenesis from the dIL progenitor domain that constitutes most of the interneurons in the superficial dorsal horn in Rexed laminae IIIV (Gross et al., 2002; Muller et al., 2002). These cells are formed from common progenitors, and their cell fates are controlled by Ascl1/Mash1 (Figure 4M; Mizuguchi et al., 2006).

\section{dIL $_{A}$ Interneuron Characteristics}

The roof-plate independent Class $\mathrm{B} \mathrm{IL}_{\mathrm{A}}$ interneurons are ipsilaterally projecting association neurons that occupy the superficial dorsal horn in Rexed laminae I-III (Gross et al., 2000). These inhibitory neurons are GABAergic and are calbindin+, and a subset express Gbx1 (John et al., 2005; Mizuguchi et al., 2006).

\section{dIL $_{A}$ Birth and Early Development}

The $\mathrm{dIL}_{\mathrm{A}}$ interneurons are late born (E.13.5) and arise from the dIL progenitor domain that is $L b x 1^{+}, L h \times 1 / 5^{+}$, and $\mathrm{Pax}^{+}$(Pillai et al., 2007). The sensory relay interneuron maker Foxd3 is downregulated in these cells (Gross et al., 2002). Pax2 has been shown to be necessary for GABAergic differentiation and 98\% of these cells also express Gad1 (GAD67; Cheng et al., 2004). The $\mathrm{dIL}_{\mathrm{A}}$ subclass is dependent on Ptfla and loss of this gene results in trans-fate to the $\mathrm{dIL}^{B}$ identity (Glasgow et al., 2005).

\section{$\mathrm{dlL}_{\mathrm{B}}$ Interneuron Characteristics}

The roof-plate independent Class $\mathrm{B}$ are $\mathrm{DRG} 11^{+}$ipsilaterally projecting association interneurons that integrate input from cutaneous sensory neurons that detect noxious stimuli (Chen et al., 2001; Gross et al., 2002). This last-born subclass gives rise to glutamatergic neurons expressing $T l \times 1$ and $T l \times 3$ and $L m \times 1 b$ (Cheng et al., 2004; Mizuguchi et al., 2006). The dIL $\mathrm{L}_{\mathrm{B}}$ neurons migrate dorsolaterally to settle in the superficial dorsal horn in Rexed laminae I-III (Gross et al., 2000; Muller et al., 2002). Over $96 \%$ of the dorsolateral population of these cells expresses both Tlx3 and VGluT2 (Cheng et al., 2004; Glasgow et al., 2005).

\section{dIL $L_{B}$ Birth and Early Development}

These neurons are born later than the dI1-6 class and express Lbx1 post-mitotically (Gross et al., 2000; Muller et al., 2002). Mash1 controls the upregulation of Notch signaling to direct formation of dILB from common dIL progenitors (Mizuguchi et al., 2006).

\section{Discussion}

Combinatorial transcriptional control of cell fate is a mature perspective for understanding spinal cord development. This focus on transcription factors has been powerful in two major respects. First, it has allowed the identification of downstream factors that direct cell-specific characteristics, such as neurotransmitter status (Cheng et al., 2004). Second, it has permitted a powerful genetic analysis of spinal neurons, using transcription factors as class-specific tools to drive changes in cell fate and function (Lee et al., 2000; Zhang et al., 2008). Novel techniques are emerging for tracing neuronal circuitry and for the sophisticated manipulation of neuronal activity, including selective cellular ablation, optogenetic activation and silencing, and chemically induced activation and silencing (Boyden et al., 2005; Wickersham et al., 2007; Alexander et al., 2009). These techniques may reach their most exciting potential when coupled with the increasingly specific genetic control available in the spinal cord.

The further refinement of developmental neuronal classes is showing that subclasses may reflect functionally coherent groups of cells that can be mapped onto physiologically identified populations (Figure 5). Therefore, as the spinal cord development field grows to incorporate circuitry and behavior, it is merging with the rich field of adult spinal cord electrophysiology that has uncovered major mechanisms of spinal cord function. The combination of these disciplines will advance spinal cord biology to a state that fully encompasses both form and function.

\section{Acknowledgments}

We apologize to the researchers whose work was not included due to space constraints. We thank Samuel Pfaff for support; and Ariel Levine, Marito Hayashi, and members of the Pfaff Laboratory for critical reading of this manuscript. 


\section{References}

Al-Mosawie, A., Wilson, J. M., and Brownstone, R. M. (2007). Heterogeneity of V2-derived interneurons in the adult mouse spinal cord. Eur. J. Neurosci. 26, 3003-3015. doi: 10.1111/j.1460-9568.2007.05907.x

Alaynick, W. A., Jessell, T. M., and Pfaff, S. L. (2011). SnapShot: spinal cord development. Cell 146, 178-178. doi: 10.1016/j.cell.2011.06.038

Alexander, G. M., Rogan, S. C., Abbas, A. I., Armbruster, B. N., Pei, Y., Allen, A. J., et al. (2009). Remote control of neuronal activity in transgenic mice expressing evolved G protein-coupled receptors. Neuron 63, 27-39. doi: 10.1016/j.neuron.2009.06.014

Alvarez, F. J., Dewey, D. E., McMillin, P., and Fyffe, R. E. (1999). Distribution of cholinergic contacts on Renshaw cells in the rat spinal cord: a light microscopic study. J. Physiol. 515(Pt 3), 787-797. doi: 10.1111/j.1469-7793.1999.787ab.x

Alvarez, F. J., Jonas, P. C., Sapir, T., Hartley, R., Berrocal, M. C., Geiman, E. J., et al. (2005). Postnatal phenotype and localization of spinal cord V1 derived interneurons. J. Comp. Neurol. 493, 177-92. doi: 10.1002/cne.20711

Andersson, L. S., Larhammar, M., Memic, F., Wootz, H., Schwochow, D., Rubin, C.-J., et al. (2012). Mutations in DMRT3 affect locomotion in horses and spinal circuit function in mice. Nature 488, 642-646. doi: 10.1038/nature 11399

Arber, S., Han, B., Mendelsohn, M., Smith, M., Jessell, T. M., and Sockanathan, S. (1999). Requirement for the homeobox gene $\mathrm{Hb} 9$ in the consolidation of motor neuron identity. Neuron 23, 659-674. doi: 10.1016/S0896-6273(01)80026-X

Ashrafi, S., Lalancette-Hebert, M., Friese, A., Sigrist, M., Arber, S., Shneider, N. A., et al. (2012). Wnt7A identifies embryonic gamma-motor neurons and reveals early postnatal dependence of gamma-motor neurons on a muscle spindlederived signal. J. Neurosci. 32, 8725-8731. doi: 10.1523/JNEUROSCI.116012.2012

Avraham, O., Hadas, Y., Vald, L., Hong, S., Song, M. R., and Klar, A. (2010). Motor and dorsal root ganglion axons serve as choice points for the ipsilateral turning of dI3 axons. J. Neurosci. 30, 15546-15557. doi: 10.1523/JNEUROSCI.238010.2010

Avraham, O., Hadas, Y., Vald, L., Zisman, S., Schejter, A., Visel, A., et al. (2009). Transcriptional control of axonal guidance and sorting in dorsal interneurons by the Lim-HD proteins Lhx9 and Lhx1. Neural Dev. 4:21. doi: 10.1186/17498104-4-21

Benito-Gonzalez, A., and Alvarez, F. J. (2012). Renshaw cells and Ia inhibitory interneurons are generated at different times from pl progenitors and differentiate shortly after exiting the cell cycle. J. Neurosci. 32, 1156-1170. doi: 10.1523/JNEUROSCI.3630-12.2012

Bermingham, N. A., Hassan, B. A., Wang, V. Y., Fernandez, M., Banfi, S., Bellen, H. J., et al. (2001). Proprioceptor pathway development is dependent on Math1. Neuron 30, 411-422. doi: 10.1016/S0896-6273(01)00305-1

Blacklaws, J., Deska-Gauthier, D., Jones, C. T., Petracca, Y. L., Liu, M., Zhang, H., et al. (2015). Sim 1 is required for the migration and axonal projections of V3 interneurons in the developing mouse spinal cord. Dev. Neurobiol. doi: 10.1002/dneu.22266 [Epub ahead of print].

Borowska, J., Jones, C. T., Zhang, H., Blacklaws, J., Goulding, M., and Zhang, Y. (2013). Functional subpopulations of V3 interneurons in the mature mouse spinal cord. J. Neurosci. 33, 18553-18565. doi: 10.1523/JNEUROSCI.200513.2013

Boyden, E. S., Zhang, F., Bamberg, E., Nagel, G., and Deisseroth, K. (2005). Millisecond-timescale, genetically targeted optical control of neural activity. Nat. Neurosci. 8, 1263-1268. doi: 10.1038/nn1525

Briscoe, J., Pierani, A., Jessell, T. M., and Ericson, J. (2000). A homeodomain protein code specifies progenitor cell identity and neuronal fate in the ventral neural tube. Cell 101, 435-45. doi: 10.1016/S0092-8674(00)80853-3

Briscoe, J., Sussel, L., Serup, P., Hartigan-O'Connor, D., Jessell, T. M., Rubenstein, J. L., et al. (1999). Homeobox gene Nkx2.2 and specification of neuronal identity by graded Sonic hedgehog signalling. Nature 398, 622-627. doi: 10.1038/19315

Brown, A. G. (1981). Organization of the Spinal Cord: The Anatomy and Physiology of Identified Neurones. New York, NY: Springer-Verlag, 238. doi: 10.1007/9781-4471-1305-8

Bui, T. V., Akay, T., Loubani, O., Hnasko, T. S., Jessell, T. M., and Brownstone, R. M. (2013). Circuits for grasping: spinal dI3 interneurons mediate cutaneous control of motor behavior. Neuron 78, 191-204. doi: 10.1016/j.neuron.2013.02.007
Burrill, J. D., Moran, L., Goulding, M. D., and Saueressig, H. (1997). PAX2 is expressed in multiple spinal cord interneurons, including a population of EN1+ interneurons that require PAX6 for their development. Development 124, 4493-4503.

Chen, Z. F., Rebelo, S., White, F., Malmberg, A. B., Baba, H., Lima, D., et al. (2001). The paired homeodomain protein DRG11 is required for the projection of cutaneous sensory afferent fibers to the dorsal spinal cord. Neuron 31, 59-73. doi: 10.1016/S0896-6273(01)00341-5

Cheng, L., Arata, A., Mizuguchi, R., Qian, Y., Karunaratne, A., Gray, P. A., et al (2004). Tlx3 and Tlx1 are post-mitotic selector genes determining glutamatergic over GABAergic cell fates. Nat. Neurosci. 7, 510-517. doi: 10.1038/nn1221

Crone, S. A., Quinlan, K. A., Zagoraiou, L., Droho, S., Restrepo, C. E., Lundfald, L., et al. (2008). Genetic ablation of V2a ipsilateral interneurons disrupts left-right locomotor coordination in mammalian spinal cord. Neuron 60, 70-83. doi: 10.1016/j.neuron.2008.08.009

Crone, S. A., Zhong, G., Harris-Warrick, R., and Sharma, K. (2009). In mice lacking V2a interneurons, gait depends on speed of locomotion. J. Neurosci. 29, 7098-7109. doi: 10.1523/JNEUROSCI.1206-09.2009

Dasen, J. S., De Camilli, A., Wang, B., Tucker, P. W., and Jessell, T. M. (2008). Hox repertoires for motor neuron diversity and connectivity gated by a single accessory factor, FoxP1. Cell 134, 304-316. doi: 10.1016/j.cell.2008.06.019

Dasen, J. S., and Jessell, T. M. (2009). Hox networks and the origins of motor neuron diversity. Curr. Top. Dev. Biol. 88, 169-200. doi: 10.1016/S00702153(09)88006-X

Dasen, J. S., Tice, B. C., Brenner-Morton, S., and Jessell, T. M. (2005). A Hox regulatory network establishes motor neuron pool identity and target-muscle connectivity. Cell 123, 477-491. doi: 10.1016/j.cell.2005.09.009

Del Barrio, M. G., Taveira-Marques, R., Muroyama, Y., Yuk, D. I., Li, S., WinesSamuelson, M., et al. (2007). A regulatory network involving Foxn4, Mash1 and delta-like 4/Notch1 generates V2a and V2b spinal interneurons from a common progenitor pool. Development 134, 3427-3436. doi: 10.1242/dev.005868

De Marco Garcia, N. V., and Jessell, T. M. (2008). Early motor neuron pool identity and muscle nerve trajectory defined by postmitotic restrictions in Nkx6.1 activity. Neuron 57, 217-231. doi: 10.1016/j.neuron.2007.11.033

Ding, Y. Q., Kim, J. Y., Xu, Y. S., Rao, Y., and Chen, Z. F. (2005). Ventral migration of early-born neurons requires Dcc and is essential for the projections of primary afferents in the spinal cord. Development 132, 2047-2056. doi: 10.1242/dev.01798

Ding, Y. Q., Yin, J., Kania, A., Zhao, Z. Q., Johnson, R. L., and Chen, Z. F. (2004). Lmxlb controls the differentiation and migration of the superficial dorsal horn neurons of the spinal cord. Development 131, 3693-3703. doi: $10.1242 /$ dev. 01250

Dottori, M., Hartley, L., Galea, M., Paxinos, G., Polizzotto, M., Kilpatrick, T., et al. (1998). EphA4 (Sek1) receptor tyrosine kinase is required for the development of the corticospinal tract. Proc. Natl. Acad. Sci. U.S.A. 95, 13248-13253. doi: 10.1073/pnas.95.22.13248

Dougherty, K. J., and Kiehn, O. (2010a). Firing and cellular properties of V2a interneurons in the rodent spinal cord. J. Neurosci. 30, 24-37. doi: 10.1523/JNEUROSCI.4821-09.2010

Dougherty, K. J., and Kiehn, O. (2010b). Functional organization of V2a-related locomotor circuits in the rodent spinal cord. Ann. N. Y. Acad. Sci. 1198, 85-93. doi: 10.1111/j.1749-6632.2010.05502.x

Duval, N., Daubas, P., Bourcier de Carbon, C., St Cloment, C., Tinevez, J. Y., Lopes, M., et al. (2014). Msx1 and Msx2 act as essential activators of Atoh1 expression in the murine spinal cord. Development 141, 1726-1736. doi: 10.1242/dev.099002

Dyck, J., Lanuza, G. M., and Gosgnach, S. (2012). Functional characterization of dI6 interneurons in the neonatal mouse spinal cord. J. Neurophysiol. 107, 3256-3266. doi: 10.1152/jn.01132.2011

Eccles, J. C., Fatt, P., and Koketsu, K. (1954). Cholinergic and inhibitory synapses in a pathway from motor-axon collaterals to motoneurones. J. Physiol. 126, 524-562. doi: 10.1113/jphysiol.1954.sp005226

Ericson, J., Morton, S., Kawakami, A., Roelink, H., and Jessell, T. M. (1996). Two critical periods of Sonic Hedgehog signaling required for the specification of motor neuron identity. Cell 87, 661-673. doi: 10.1016/S0092-8674(00)81386-0

Ericson, J., Thor, S., Edlund, T., Jessell, T. M., and Yamada, T. (1992). Early stages of motor neuron differentiation revealed by expression of homeobox gene Islet-1. Science 256, 1555-1560. doi: 10.1126/science.1350865 
Francius, C., and Clotman, F. (2010). Dynamic expression of the Onecut transcription factors HNF-6, OC-2 and OC-3 during spinal motor neuron development. Neuroscience 165, 116-129. doi: 10.1016/j.neuroscience.2009.09.076

Francius, C., Harris, A., Rucchin, V., Hendricks, T. J., Stam, F. J., Barber, M., et al. (2013). Identification of multiple subsets of ventral interneurons and differential distribution along the rostrocaudal axis of the developing spinal cord. PLoS ONE 8:e70325. doi: 10.1371/journal.pone.0070325

Francius, C., Ravassard, P., Hidalgo-Figueroa, M., Mallet, J., Clotman, F., and Nardelli, J. (2014). Genetic dissection of Gata2 selective functions during specification of V2 interneurons in the developing spinal cord. Dev. Neurobiol. doi: 10.1002/dneu.22244 [Epub ahead of print].

Friese, A., Kaltschmidt, J. A., Ladle, D. R., Sigrist, M., Jessell, T. M., and Arber, S. (2009). Gamma and alpha motor neurons distinguished by expression of transcription factor Err3. Proc .Natl. Acad. Sci. U.S.A. 106, 13588-13593. doi: 10.1073/pnas.0906809106

Geiman, E. J., Knox, M. C., and Alvarez, F. J. (2000). Postnatal maturation of gephyrin/glycine receptor clusters on developing Renshaw cells. J. Comp. Neurol. 426, 130-142. doi: 10.1002/1096-9861(20001009)426:1<130::AIDCNE9>3.0.CO;2-7

Glasgow, S. M., Henke, R. M., Macdonald, R. J., Wright, C. V., and Johnson, J. E. (2005). Ptfla determines GABAergic over glutamatergic neuronal cell fate in the spinal cord dorsal horn. Development 132, 5461-5469. doi: 10.1242/dev.02167

Gosgnach, S., Lanuza, G. M., Butt, S. J., Saueressig, H., Zhang, Y., Velasquez, T., et al. (2006). V1 spinal neurons regulate the speed of vertebrate locomotor outputs. Nature 440, 215-219. doi: 10.1038/nature04545

Gould, T. W., Buss, R. R., Vinsant, S., Prevette, D., Sun, W., Knudsonet, M., et al. (2006). Complete dissociation of motor neuron death from motor dysfunction by Bax deletion in a mouse model of ALS. J. Neurosci. 26, 8774-8786. doi: 10.1523/JNEUROSCI.2315-06.2006

Gould, T. W., Yonemura, S., Oppenheim, R. W., Ohmori, S., and Enomoto, H. (2008). The neurotrophic effects of glial cell line-derived neurotrophic factor on spinal motoneurons are restricted to fusimotor subtypes. J. Neurosci. 28, 2131-2146. doi: 10.1523/JNEUROSCI.5185-07.2008

Goulding, M. (2009). Circuits controlling vertebrate locomotion: moving in a new direction. Nat. Rev. Neurosci. 10, 507-518. doi: 10.1038/nrn2608

Goulding, M., Lanuza, G., Sapir, T., and Narayan, S. (2002). The formation of sensorimotor circuits. Curr. Opin. Neurobiol. 12, 508-515. doi: 10.1016/S09594388(02)00371-9

Goulding, M., and Pfaff, S. L. (2005). Development of circuits that generate simple rhythmic behaviors in vertebrates. Curr. Opin. Neurobiol. 15, 14-20. doi: 10.1016/j.conb.2005.01.017

Gowan, K., Helms, A. W., Hunsaker, T. L., Collisson, T., Ebert, P. J., Odom, R., et al. (2001). Crossinhibitory activities of Ngn1 and Math1 allow specification of distinct dorsal interneurons. Neuron 31, 219-232. doi: 10.1016/S08966273(01)00367-1

Griener, A., Zhang, W., Kao, H., Wagner, C., and Gosgnach, S. (2015). Probing diversity within subpopulations of locomotor-related V0 interneurons. Dev. Neurobiol. doi: 10.1002/dneu.22277 [Epub ahead of print].

Grillner, S., and Jessell, T. M. (2009). Measured motion: searching for simplicity in spinal locomotor networks. Curr. Opin. Neurobiol. 19, 572-586. doi: 10.1016/j.conb.2009.10.011

Gross, M. K., Dottori, M., and Goulding, M. (2002). Lbx1 specifies somatosensory association interneurons in the dorsal spinal cord. Neuron 34, 535-49. doi: 10.1016/S0896-6273(02)00690-6

Gross, M. K., Moran-Rivard, L., Velasquez, T., Nakatsu, M. N., Jagla, K., and Goulding, M. (2000). Lbx1 is required for muscle precursor migration along a lateral pathway into the limb. Development 127, 413-424.

Hanson, M. G., and Landmesser, L. T. (2004). Normal patterns of spontaneous activity are required for correct motor axon guidance and the expression of specific guidance molecules. Neuron 43, 687-701. doi: 10.1016/j.neuron.2004.08.018

Hegarty, S. V., O'Keeffe, G. W., and Sullivan, A. M. (2013). BMP-Smad 1/5/8 signalling in the development of the nervous system. Prog. Neurobiol. 109, 28-41. doi: 10.1016/j.pneurobio.2013.07.002

Helms, A. W., Battiste, J., Henke, R. M., Nakada, Y., Simplicio, N., Guillemot, F., et al. (2005). Sequential roles for Mash1 and Ngn2 in the generation of dorsal spinal cord interneurons. Development 132, 2709-2719. doi: 10.1242/dev.01859
Helms, A. W., and Johnson, J. E. (1998). Progenitors of dorsal commissural interneurons are defined by MATH1 expression. Development 125, 919-928.

Helms, A. W., and Johnson, J. E. (2003). Specification of dorsal spinal cord interneurons. Curr. Opin. Neurobiol. 13, 42-49. doi: 10.1016/S09594388(03)00010-2

Henke, R. M., Savage, T. K., Meredith, D. M., Glasgow, S. M., Hori, K., Dumas, J., et al. (2009). Neurog2 is a direct downstream target of the Ptfla-Rbpj transcription complex in dorsal spinal cord. Development 136, 2945-2954. doi: $10.1242 /$ dev. 035352

Hinckley, C. A., Hartley, R., Wu, L., Todd, A., and Ziskind-Conhaim, L. (2005). Locomotor-like rhythms in a genetically distinct cluster of interneurons in the mammalian spinal cord. J. Neurophysiol. 93, 1439-1449. doi: $10.1152 /$ jn.00647.2004

Hinckley, C. A., and Ziskind-Conhaim, L. (2006). Electrical coupling between locomotor-related excitatory interneurons in the mammalian spinal cord. J. Neurosci. 26, 8477-8483. doi: 10.1523/JNEUROSCI.0395-06.2006

Holz, A., Kollmus, H., Ryge, J., Niederkofler, V., Dias, J., Ericson, J., et al. (2010). The transcription factors $\mathrm{Nkx2.2}$ and $\mathrm{Nkx} 2.9$ play a novel role in floor plate development and commissural axon guidance. Development 137, 4249-4260. doi: 10.1242/dev.053819

Hultborn, H., Jankowska, E., and Lindstrom, S. (1971). Recurrent inhibition of interneurones monosynaptically activated from group Ia afferents. J. Physiol. 215, 613-636. doi: 10.1113/jphysiol.1971.sp009488

Hultborn, H., and Udo, M. (1972). Convergence of large muscle spindle (Ia) afferents at interneuronal level in the reciprocal Ia inhibitory pathway to motoneurones. Acta Physiol. Scand. 84, 493-499. doi: 10.1111/j.17481716.1972.tb05199.x

Jankowska, E. (2001). Spinal interneuronal systems: identification, multifunctional character and reconfigurations in mammals. J. Physiol. 533, 31-40. doi: 10.1111/j.1469-7793.2001.0031b.x

Jessell, T. M. (2000). Neuronal specification in the spinal cord: inductive signals and transcriptional codes. Nat. Rev. Genet. 1, 20-29. doi: 10.1038/35049541

Ji, S. J., Zhuang, B., Falco, C., Schneider, A., Schuster-Gossler, K., Gossler, A., et al. (2006). Mesodermal and neuronal retinoids regulate the induction and maintenance of limb innervating spinal motor neurons. Dev. Biol. 297, 249-261. doi: 10.1016/j.ydbio.2006.05.015

John, A., Wildner, H., and Britsch, S. (2005). The homeodomain transcription factor Gbxl identifies a subpopulation of late-born GABAergic interneurons in the developing dorsal spinal cord. Dev. Dyn. 234, 767-771. doi: $10.1002 /$ dvdy. 20568

Jung, H., Lacombe, J., Mazzoni, E. O., Liem, K. F. Jr., Grinstein, J., Mahony, S., et al. (2010). Global control of motor neuron topography mediated by the repressive actions of a single hox gene. Neuron 67, 781-796. doi: 10.1016/j.neuron.2010.08.008

Kang, K., Lee, D., Hong, S., Park, S. G., and Song, M. R. (2013). The E3 ligase Mind bomb-1 (Mib1) modulates Delta-Notch signaling to control neurogenesis and gliogenesis in the developing spinal cord. J. Biol. Chem. 288, 2580-2592. doi: $10.1074 /$ jbc.M112.398263

Kiehn, O. (2006). Locomotor circuits in the mammalian spinal cord. Annu. Rev. Neurosci. 29, 279-306. doi: 10.1146/annurev.neuro.29.051605.112910

Kimura, Y., Okamura, Y., and Higashijima, S. (2006). alx, a zebrafish homolog of Chx10, marks ipsilateral descending excitatory interneurons that participate in the regulation of spinal locomotor circuits. J. Neurosci. 26, 5684-5697. doi: 10.1523/JNEUROSCI.4993-05.2006

Kimura, Y., Satou, C., and Higashijima, S. (2008). V2a and V2b neurons are generated by the final divisions of pair-producing progenitors in the zebrafish spinal cord. Development 135, 3001-3005. doi: 10.1242/dev.024802

Kriks, S., Lanuza, G. M., Mizuguchi, R., Nakafuku, M., and Goulding, M. (2005). Gsh2 is required for the repression of Ngn1 and specification of dorsal interneuron fate in the spinal cord. Development 132, 2991-3002. doi: $10.1242 /$ dev. 01878

Kullander, K., Croll, S. D., Zimmer, M., Pan, L., McClain, J., Hughes, V., et al. (2001). Ephrin-B3 is the midline barrier that prevents corticospinal tract axons from recrossing, allowing for unilateral motor control. Genes Dev. 15, 877-888. doi: 10.1101/gad.868901

Kwan, A. C., Dietz, S. B., Webb, W. W., and Harris-Warrick, R. M. (2009). Activity of $\mathrm{Hb} 9$ interneurons during fictive locomotion in mouse spinal cord. J. Neurosci. 29, 11601-11613. doi: 10.1523/JNEUROSCI.1612-09.2009 
Ladle, D. R., Pecho-Vrieseling, E., and Arber, S. (2007). Assembly of motor circuits in the spinal cord: driven to function by genetic and experiencedependent mechanisms. Neuron 56, 270-283. doi: 10.1016/j.neuron.2007. 09.026

Landmesser, L. (1978). The distribution of motoneurones supplying chick hind limb muscles. J. Physiol. 284, 371-389. doi: 10.1113/jphysiol.1978. sp012545

Lanuza, G. M., Gosgnach, S., Pierani, A., Jessell, T. M., and Goulding, M. (2004). Genetic identification of spinal interneurons that coordinate left-right locomotor activity necessary for walking movements. Neuron $42,375-386$. doi: 10.1016/S0896-6273(04)00249-1

Le Dréau, G., Garcia-Campmany, L., Rabadán, M. A., Ferronha, T., Tozer, S. Briscoe, J., et al. (2012). Canonical BMP7 activity is required for the generation of discrete neuronal populations in the dorsal spinal cord. Development 139 259-268. doi: $10.1242 / \mathrm{dev} .074948$

Lee, K. J., Dietrich, P., and Jessell, T. M. (2000). Genetic ablation reveals that the roof plate is essential for dorsal interneuron specification. Nature 403, 734-740. doi: $10.1038 / 35001507$

Lee, K. J., Mendelsohn, M., and Jessell, T. M. (1998). Neuronal patterning by BMPs: a requirement for GDF7 in the generation of a discrete class of commissural interneurons in the mouse spinal cord. Genes Dev. 12, 3394-3407. doi: 10.1101/gad.12.21.3394

Lee, S., Lee, B., Joshi, K., Pfaff, S. L., Lee, J. W., and Lee, S. K. (2008). A regulatory network to segregate the identity of neuronal subtypes. Dev. Cell 14, 877-889. doi: 10.1016/j.devcel.2008.03.021

Lee, S. K., and Pfaff, S. L. (2001). Transcriptional networks regulating neuronal identity in the developing spinal cord. Nat. Neurosci. 4(Suppl.), 1183-1191. doi: $10.1038 / \mathrm{nn} 750$

Li, S., Misra, K., and Xiang, M. (2010). A Cre transgenic line for studying V2 neuronal lineages and functions in the spinal cord. Genesis 48, 667-672. doi: $10.1002 / \mathrm{dvg} .20669$

Liem, K. F. Jr., Tremml, G., and Jessell, T. M. (1997). A role for the roof plate and its resident TGFbeta-related proteins in neuronal patterning in the dorsal spinal cord. Cell 91, 127-138. doi: 10.1016/S0092-8674(01)80015-5

Liem, K. F. Jr., Tremml, G., Roelink, H., and Jessell, T. M. (1995). Dorsal differentiation of neural plate cells induced by BMP-mediated signals from epidermal ectoderm. Cell 82, 969-979. doi: 10.1016/0092-8674(95)90276-7

Lin, J. H., Saito, T., Anderson, D. J., Lance-Jones, C., Jessell, T. M., and Arber, S. (1998). Functionally related motor neuron pool and muscle sensory afferent subtypes defined by coordinate ETS gene expression. Cell 95, 393-407. doi 10.1016/S0092-8674(00)81770-5

Liu, J. P., Laufer, E., and Jessell, T. M. (2001). Assigning the positional identity of spinal motor neurons: rostrocaudal patterning of Hox-c expression by FGFs, Gdf11, and retinoids. Neuron 32, 997-1012. doi: 10.1016/S08966273(01)00544-X

Liu, Z., Hu, X., Huang, C., Zheng, K., Takebayashi, H., Cao, C., et al. (2014). Olig3 is not involved in the ventral patterning of spinal cord. PLOS ONE 9:e111076. doi: 10.1371/journal.pone. 0111076

Lundfald, L., Restrepo, C. E., Butt, S. J., Peng, C. Y., Droho, S., Endo, T., et al. (2007). Phenotype of V2-derived interneurons and their relationship to the axon guidance molecule EphA4 in the developing mouse spinal cord. Eur. J. Neurosci. 26, 2989-3002. doi: 10.1111/j.1460-9568.2007. 05906.x

Marion, J. F., Yang, C., Caqueret, A., Boucher, F., and Michaud, J. L. (2005). Sim1 and Sim2 are required for the correct targeting of mammillary body axons. Development 132, 5527-5537. doi: 10.1242/dev.02142

Matise, M. P., and Joyner, A. L. (1997). Expression patterns of developmental control genes in normal and Engrailed-1 mutant mouse spinal cord reveal early diversity in developing interneurons. J. Neurosci. 17, 7805-7816.

McLean, D. L., Masino, M. A., Koh, I. Y., Lindquist, W. B., and Fetcho, J. R. (2008). Continuous shifts in the active set of spinal interneurons during changes in locomotor speed. Nat. Neurosci. 11, 1419-1429. doi: 10.1038/nn.2225

Megason, S. G., and McMahon, A. P. (2002). A mitogen gradient of dorsal midline Wnts organizes growth in the CNS. Development 129, 2087-2098.

Mentis, G. Z., Alvarez, F. J., Bonnot, A., Richards, D. S., Gonzalez-Forero, D. Zerda, R., et al. (2005). Noncholinergic excitatory actions of motoneurons in the neonatal mammalian spinal cord. Proc. Natl. Acad. Sci. U.S.A. 102, 7344-7349. doi: $10.1073 /$ pnas.0502788102
Meredith, D. M., Masui, T., Swift, G. H., MacDonald, R. J., and Johnson, J. E. (2009). Multiple transcriptional mechanisms control Ptfla levels during neural development including autoregulation by the PTF1-J complex. J. Neurosci. 29, 11139-11148. doi: 10.1523/JNEUROSCI.2303-09.2009

Miesegaes, G. R., Klisch, T. J., Thaller, C., Ahmad, K. A., Atkinson, R. C., and Zoghbi, H. Y. (2009). Identification and subclassification of new Atoh1 derived cell populations during mouse spinal cord development. Dev. Biol. 327, 339351. doi: 10.1016/j.ydbio.2008.12.016

Misra, M., Shah, V., Carpenter, E., McCaffery, P., and Lance-Jones, C. (2009). Restricted patterns of Hoxd10 and Hoxd11 set segmental differences in motoneuron subtype complement in the lumbosacral spinal cord. Dev. Biol. 330, 54-72. doi: 10.1016/j.ydbio.2009.03.009

Mizuguchi, R., Kriks, S., Cordes, R., Gossler, A., Ma, Q., and Goulding, M. (2006). Ascl1 and Gsh1/2 control inhibitory and excitatory cell fate in spinal sensory interneurons. Nat. Neurosci. 9, 770-778. doi: 10.1038/nn1706

Moran-Rivard, L., Kagawa, T., Saueressig, H., Gross, M. K., Burrill, J., Goulding, M., et al. (2001). Evx1 is a postmitotic determinant of v0 interneuron identity in the spinal cord. Neuron 29, 385-399. doi: 10.1016/S08966273(01)00213-6

Morikawa, Y., Hisaoka, T., and Senba, E. (2009). Characterization of Foxp2expressing cells in the developing spinal cord. Neuroscience 162, 1150-1162. doi: 10.1016/j.neuroscience.2009.05.022

Muhr, J., Graziano, E., Wilson, S., Jessell, T. M., and Edlund, T. (1999). Convergent inductive signals specify midbrain, hindbrain, and spinal cord identity in gastrula stage chick embryos. Neuron 23, 689-702. doi: 10.1016/S08966273(01)80028-3

Muller, T., Anlag, K., Wildner, H., Britsch, S., Treier, M., and Birchmeier, C. (2005). The bHLH factor Olig3 coordinates the specification of dorsal neurons in the spinal cord. Genes Dev. 19, 733-743. doi: 10.1101/gad.326105

Muller, T., Brohmann, H., Pierani, A., Heppenstall, P. A., Lewin, G. R., et al. (2002). The homeodomain factor lbxl distinguishes two major programs of neuronal differentiation in the dorsal spinal cord. Neuron 34, 551-562. doi: 10.1016/S0896-6273(02)00689-X

Muroyama, Y., Fujihara, M., Ikeya, M., Kondoh, H., and Takada, S. (2002). Wnt signaling plays an essential role in neuronal specification of the dorsal spinal cord. Genes Dev. 16, 548-553. doi: 10.1101/gad.937102

Myers, C. P., Lewcock, J. W., Hanson, M. G., Gosgnach, S., Aimone, J. B., Gage, H. F., et al. (2005). Cholinergic input is required during embryonic development to mediate proper assembly of spinal locomotor circuits. Neuron 46, 37-49. doi: 10.1016/j.neuron.2005.02.022

Nornes, H. O., and Carry, M. (1978). Neurogenesis in spinal cord of mouse: an autoradiographic analysis. Brain Res. 159, 1-6. doi: 10.1016/00068993(78)90105-1

Novitch, B. G., Chen, A. I., and Jessell, T. M. (2001). Coordinate regulation of motor neuron subtype identity and pan-neuronal properties by the bHLH repressor Olig2. Neuron 31, 773-789. doi: 10.1016/S0896-6273(01) 00407-X

Okigawa, S., Mizoguchi, T., Okano, M., Tanaka, H., Isoda, M., Isoda, M., Jiang, Y. J., et al. (2014). Different combinations of Notch ligands and receptors regulate V2 interneuron progenitor proliferation and V2a/V2b cell fate determination. Dev. Biol. 391, 196-206. doi: 10.1016/j.ydbio.2014.04.011

Panayi, H., Panayiotou, E., Orford, M., Genethliou, N., Mean, R., Lapathitis, G., et al. (2010). Sox1 is required for the specification of a novel p2-derived interneuron subtype in the mouse ventral spinal cord. J. Neurosci. 30, 1227412280. doi: 10.1523/JNEUROSCI.2402-10.2010

Peng, C. Y., Yajima, H., Burns, C. E., Zon, L. I., Sisodia, S. S., Pfaff, S. L., et al. (2007). Notch and MAML signaling drives Scl-dependent interneuron diversity in the spinal cord. Neuron 53, 813-827. doi: 10.1016/j.neuron.2007.02.019

Pfaff, S. L., Mendelsohn, M., Stewart, C. L., Edlund, T., and Jessell, T. M. (1996). Requirement for LIM homeobox gene Isl1 in motor neuron generation reveals a motor neuron-dependent step in interneuron differentiation. Cell 84, 309-320. doi: 10.1016/S0092-8674(00)80985-X

Pierani, A., Brenner-Morton, S., Chiang, C., and Jessell, T. M. (1999). A sonic hedgehog-independent, retinoid-activated pathway of neurogenesis in the ventral spinal cord. Cell 97, 903-915. doi: 10.1016/S0092-8674(00) 80802-8

Pierani, A., Moran-Rivard, L., Sunshine, M. J., Littman, D. R., Goulding, M., and Jessell, T. M. (2001). Control of interneuron fate in the developing spinal 
cord by the progenitor homeodomain protein Dbx1. Neuron 29, 367-384. doi: 10.1016/S0896-6273(01)00212-4

Pillai, A., Mansouri, A., Behringer, R., Westphal, H., and Goulding, M. (2007). Lhx1 and Lhx 5 maintain the inhibitory-neurotransmitter status of interneurons in the dorsal spinal cord. Development 134, 357-366. doi: 10.1242/dev. 02717

Qian, Y., Shirasawa, S., Chen, C. L., Cheng, L., and Ma, Q. (2002). Proper development of relay somatic sensory neurons and D2/D4 interneurons requires homeobox genes Rnx/Tlx-3 and Tlx-1. Genes Dev. 16, 1220-1233. doi: $10.1101 /$ gad. 982802

Quiroga, A. C., Stolt, C. C., Del Corral, R. D., Dimitrov, S., Perez-Alcala, S., Sock, E., et al. (2015). Sox 5 controls dorsal progenitor and interneuron specification in the spinal cord. Dev. Neurobiol. 75, 522-538. doi: 10.1002/dneu.22240

Ramos, C., Rocha, S., Gaspar, C., and Henrique, D. (2010). Two Notch ligands, Dll1 and Jag1, are differently restricted in their range of action to control neurogenesis in the mammalian spinal cord. PLOS ONE 5:e15515. doi: 10.1371/journal.pone. 0015515

Richards, D. S., Griffith, R. W., Romer, S. H., and Alvarez, F. J. (2014). Motor axon synapses on renshaw cells contain higher levels of aspartate than glutamate. PLoS ONE 9:e97240. doi: 10.1371/journal.pone.0097240

Roelink, H., Augsburger, A., Heemskerk, J., Korzh, V., Norlin, S., Ruiz i Altaba, A., et al. (1994). Floor plate and motor neuron induction by vhh-1, a vertebrate homolog of hedgehog expressed by the notochord. Cell 76, 761-775. doi: 10.1016/0092-8674(94)90514-2

Sander, M., Paydar, S., Ericson, J., Briscoe, J., Berber, E., German, M., et al. (2000). Ventral neural patterning by Nkx homeobox genes: Nkx6.1 controls somatic motor neuron and ventral interneuron fates. Genes Dev. 14, 2134-2139. doi: 10.1101/gad. 820400

Sapir, T., Geiman, E. J., Wang, Z., Velasquez, T., Mitsui, S., Yoshihara, Y., et al. (2004). Pax6 and engrailed 1 regulate two distinct aspects of renshaw cell development. J. Neurosci. 24, 1255-1264. doi: 10.1523/JNEUROSCI.318703.2004

Saueressig, H., Burrill, J., and Goulding, M. (1999). Engrailed-1 and netrin-1 regulate axon pathfinding by association interneurons that project to motor neurons. Development 126, 4201-4212.

Scardigli, R., Schuurmans, C., Gradwohl, G., and Guillemot, F. (2001). Crossregulation between Neurogenin2 and pathways specifying neuronal identity in the spinal cord. Neuron 31, 203-217. doi: 10.1016/S08966273(01)00358-0

Sharma, K., Leonard, A. E., Lettieri, K., and Pfaff, S. L. (2000). Genetic and epigenetic mechanisms contribute to motor neuron pathfinding. Nature 406, 515-519. doi: 10.1038/35020078

Sharma, K., Sheng, H. Z., Lettieri, K., Li, H., Karavanov, A., Potter, S., et al. (1998). LIM homeodomain factors Lhx3 and Lhx4 assign subtype identities for motor neurons. Cell 95, 817-828. doi: 10.1016/S0092-8674(00)81704-3

Shirasaki, R., and Pfaff, S. L. (2002). Transcriptional codes and the control of neuronal identity. Annu. Rev. Neurosci. 25, 251-281. doi: 10.1146/annurev.neuro.25.112701.142916

Shneider, N. A., Brown, M. N., Smith, C. A., Pickel, J., and Alvarez, F. J. (2009). Gamma motor neurons express distinct genetic markers at birth and require muscle spindle-derived GDNF for postnatal survival. Neural Dev. 4, 42. doi: $10.1186 / 1749-8104-4-42$

Skaggs, K., Martin, D. M., and Novitch, B. G. (2011). Regulation of spinal interneuron development by the Olig-related protein Bhlhb5 and Notch signaling. Development 138, 3199-3211. doi: 10.1242/dev.057281

Sockanathan, S., and Jessell, T. M. (1998). Motor neuron-derived retinoid signaling specifies the subtype identity of spinal motor neurons. Cell 94, 503-514. doi: 10.1016/S0092-8674(00)81591-3

Sockanathan, S., Perlmann, T., and Jessell, T. M. (2003). Retinoid receptor signaling in postmitotic motor neurons regulates rostrocaudal positional identity and axonal projection pattern. Neuron 40, 97-111. doi: 10.1016/S08966273(03)00532-4

Stam, F. J., Hendricks, T. J., Zhang, J., Geiman, E. J., Francius, C., Labosky, P. A., et al. (2012). Renshaw cell interneuron specialization is controlled by a temporally restricted transcription factor program. Development 139, 179-190. doi: $10.1242 /$ dev.071134

Stepien, A. E., and Arber, S. (2008). Probing the locomotor conundrum: descending the ' $V$ ' interneuron ladder. Neuron 60, 1-4. doi: 10.1016/j.neuron.2008.09.030
Stepien, A. E., Tripodi, M., and Arber, S. (2010). Monosynaptic rabies virus reveals premotor network organization and synaptic specificity of cholinergic partition cells. Neuron 68, 456-472. doi: 10.1016/j.neuron.2010.10.019

Tanabe, Y., William, C., and Jessell, T. M. (1998). Specification of motor neuron identity by the MNR2 homeodomain protein. Cell 95, 67-80. doi: 10.1016/S0092-8674(00)81783-3

Thaler, J., Harrison, K., Sharma, K., Lettieri, K., Kehrl, J., and Pfaff, S. L. (1999). Active suppression of interneuron programs within developing motor neurons revealed by analysis of homeodomain factor HB9. Neuron 23, 675-687. doi: 10.1016/S0896-6273(01)80027-1

Thaler, J. P., Koo, S. J., Kania, A., Lettieri, K., Andrews, S., Cox, C., et al. (2004). A postmitotic role for Isl-class LIM homeodomain proteins in the assignment of visceral spinal motor neuron identity. Neuron 41, 337-350. doi: 10.1016/S08966273(04)00011-X

Thaler, J. P., Lee, S. K., Jurata, L. W., Gill, G. N., and Pfaff, S. L. (2002). LIM factor Lhx 3 contributes to the specification of motor neuron and interneuron identity through cell-type-specific protein-protein interactions. Cell 110, 237-249. doi: 10.1016/S0092-8674(02)00823-1

Timmer, J. R., Wang, C., and Niswander, L. (2002). BMP signaling patterns the dorsal and intermediate neural tube via regulation of homeobox and helix-loophelix transcription factors. Development 129, 2459-2472.

Tracey, D. P. (1985). “The somatosensory system." in The Rat Nervous System, ed. G. Paxinos (San Diego, CA: Academic Press), 129-152.

Tsuchida, T., Ensini, M., Morton, S. B., Baldassare, M., Edlund, T., Jessell, T. M., et al. (1994). Topographic organization of embryonic motor neurons defined by expression of LIM homeobox genes. Cell 79, 957-970. doi: 10.1016/00928674(94)90027-2

Vallstedt, A., and Kullander, K. (2013). Dorsally derived spinal interneurons in locomotor circuits. Ann. N. Y. Acad. Sci. 1279, 32-42. doi: 10.1111/j.17496632.2012.06801.x

Vallstedt, A., Muhr, J., Pattyn, A., Pierani, A., Mendelsohn, M., Sander, M., et al. (2001). Different levels of repressor activity assign redundant and specific roles to Nkx6 genes in motor neuron and interneuron specification. Neuron 31, 743-755. doi: 10.1016/S0896-6273(01)00412-3

Wang, Z., Li, L., Goulding, M., and Frank, E. (2008). Early postnatal development of reciprocal Ia inhibition in the murine spinal cord. J. Neurophysiol. 100, 185-196. doi: 10.1152/jn. 90354.2008

Watterson, R. L. (1965). Organogenesis. New York, NY: Holt, Rinehart and Winston, 129-159.

Wenner, P., Matise, M. P., Joyner, A., and O’Donovan, M. J. (1998). Physiological and molecular characterization of interneurons in the developing spinal cord. Ann. N. Y. Acad. Sci. 860, 425-427. doi: 10.1111/j.1749-6632.1998.tb 09066.x

Wenner, P., O’Donovan, M. J., and Matise, M. P. (2000). Topographical and physiological characterization of interneurons that express engrailed- 1 in the embryonic chick spinal cord. J. Neurophysiol. 84, 2651-2657.

Wichterle, H., Lieberam, I., Porter, J. A., and Jessell, T. M. (2002). Directed differentiation of embryonic stem cells into motor neurons. Cell 110, 385-397. doi: 10.1016/S0092-8674(02)00835-8

Wickersham, I. R., Lyon, D. C., Barnard, R. J., Mori, T., Finke, S., Conzelmann, K. K., et al. (2007). Monosynaptic restriction of transsynaptic tracing from single, genetically targeted neurons. Neuron 53, 639-647. doi: 10.1016/j.neuron.2007.01.033

Wilson, J. M., Hartley, R., Maxwell, D. J., Todd, A. J., Lieberam, I., Kaltschmidt, J. A., et al. (2005). Conditional rhythmicity of ventral spinal interneurons defined by expression of the $\mathrm{Hb} 9$ homeodomain protein. J. Neurosci. 25, 5710-5719. doi: 10.1523/JNEUROSCI.0274-05.2005

Wilson, S. I., Shafer, B., Lee, K. J., and Dodd, J. (2008). A molecular program for contralateral trajectory: Rig-1 control by LIM homeodomain transcription factors. Neuron 59, 413-424. doi: 10.1016/j.neuron.2008.07.020

Yang, X., Tomita, T., Wines-Samuelson, M., Beglopoulos, V., Tansey, M. G., Kopan, R., et al. (2006). Notch1 signaling influences v2 interneuron and motor neuron development in the spinal cord. Dev. Neurosci. 28, 102-117. doi: $10.1159 / 000090757$

Yokoyama, N., Romero, M. I., Cowan, C. A., Galvan, P., Helmbacher, F., Charnay, P., et al. (2001). Forward signaling mediated by ephrin-B3 prevents contralateral corticospinal axons from recrossing the spinal cord midline. Neuron 29, 85-97. doi: 10.1016/S0896-6273(01)00182-9 
Zagoraiou, L., Akay, T., Martin, J. F., Brownstone, R. M., Jessell, T. M., and Miles, G. B. (2009). A cluster of cholinergic premotor interneurons modulates mouse locomotor activity. Neuron 64, 645-662. doi: 10.1016/j.neuron.2009.10.017

Zhang, J., Lanuza, G. M., Britz, O., Wang, Z., Siembab, V. C., Zhang, Y., et al. (2014). V1 and v2b interneurons secure the alternating flexor-extensor motor activity mice require for limbed locomotion. Neuron 82, 138-150. doi: 10.1016/j.neuron.2014.02.013

Zhang, Y., Narayan, S., Geiman, E., Lanuza, G. M., Velasquez, T., Shanks, B., et al. (2008). V3 spinal neurons establish a robust and balanced locomotor rhythm during walking. Neuron 60, 84-96. doi: 10.1016/j.neuron.2008.09.027

Zhong, G., Droho, S., Crone, S. A., Dietz, S., Kwan, A. C., Kwan, A. C., et al. (2010). Electrophysiological characterization of V2a interneurons and their locomotorrelated activity in the neonatal mouse spinal cord. J. Neurosci. 30, 170-182. doi: 10.1523/JNEUROSCI.4849-09.2010
Zou, M., Luo, H., and Xiang, M. (2015). Selective neuronal lineages derived from Dll4-expressing progenitors/precursors in the retina and spinal cord. Dev. Dyn. 244, 86-97. doi: $10.1002 /$ dvdy. 24185

Conflict of Interest Statement: The authors declare that the research was conducted in the absence of any commercial or financial relationships that could be construed as a potential conflict of interest.

Copyright $\odot 2015 \mathrm{Lu}$, Niu and Alaynick. This is an open-access article distributed under the terms of the Creative Commons Attribution License (CC BY). The use, distribution or reproduction in other forums is permitted, provided the original author(s) or licensor are credited and that the original publication in this journal is cited, in accordance with accepted academic practice. No use, distribution or reproduction is permitted which does not comply with these terms. 